\title{
GINÁSTICA LABORAL PARA CAVALOS TERAPEUTAS
}

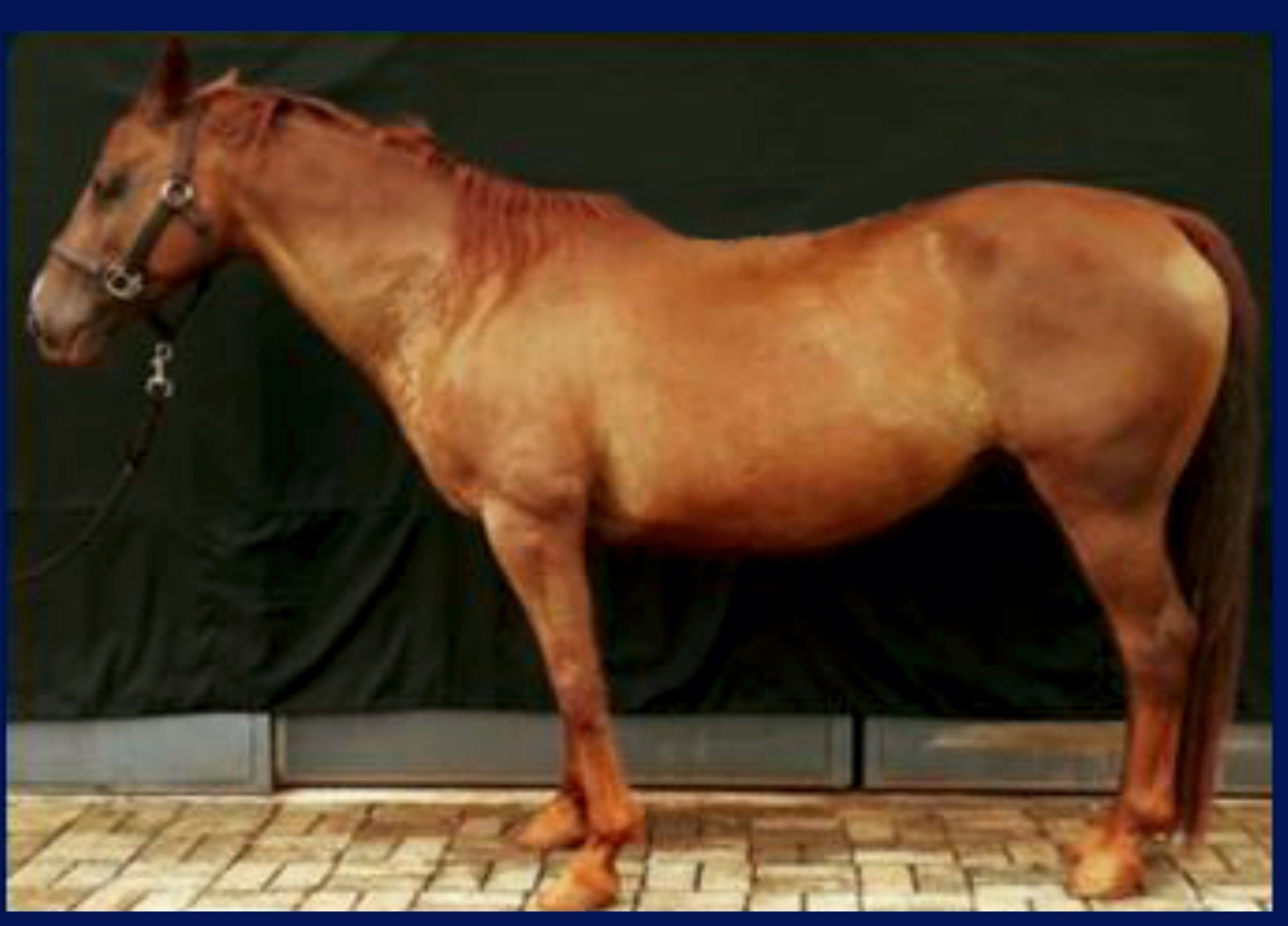

REVISÃO CIENTÍFICA

Prof ${ }^{a}$. Ora. Kátia de Oliveina 
Kátia de Oliveira

\section{GINÁSTICA LABORAL PARA CAVALOS TERAPEUTAS}

REVISÃO CIENTÍFICA

1a edição 


\author{
(C) 2020 por Kátia de Olivera \\ Todos os direitos reservados. \\ Conselho editorial \\ Colaboradores: \\ Márcia Aparecida da Silva Pimentel \\ Universidade Federal do Pará - UFPA \\ José Antônio Herrera \\ Universidade Federal do Pará - UFPA \\ Wildoberto Batista Gurgel \\ Universidade Federal Rural do Semi-Árido - UFERSA \\ André Luiz de Oliveira Brum \\ Universidade Federal do Rondônia - UNIR \\ Mário Silva Uacane \\ Universidade Licungo / Moçambique \\ Francisco da Silva Costa \\ Universidade do Minho / Portugal \\ Ofelia Pérez Montero \\ Universidad de Oriente- Santiago de Cuba-Cuba \\ Editora-chefe \\ Viviane Corrêa Santos \\ (Universidade do Estado do Pará - UEPA) \\ Editoração eletrônica: Walter Rodrigues \\ Capa: da autora
}

Dados Internacionais de Catalogação na Publicação (CIP) de acordo com ISBD

O48g Oliveira, Kátia de

Ginástica laboral para cavalos terapeutas [recurso eletrônico] / Kátia de Oliveira. - Ananindeua, PA : Itacaiúnas, 2020.

80 p. : il. ; PDF ; 3 MB.

Inclui índice e bibliografia.

ISBN: 978-65-990164-5-5 (Ebook) Título.

1. Medicina. 2. Terapia. 3. Ginástica laboral. 4. Cavalos terapeutas. I.

CDD 615.5

CDU 615.5

Elaborado por Vagner Rodolfo da Silva - CRB-8/9410

Índice para catálogo sistemático:

1. Medicina : Terapia 615.5

2. Medicina : Terapia 615.5

DOI: 10.36599/itac-ed1.003

O conteúdo desta obra, inclusive sua revisão ortográfica e gramatical, bem como os dados apresentados, são de responsabilidade de seus participantes, detentores dos Direitos Autorais.

Esta obra foi publicada pela Editora Itacaiúnas em abril de 2020. 


\section{PREFÁCIO}

A temática sobre a importância da atividade específica às necessidades de cavalos terapeutas é abordada nesta publicação. Neste sentido, a ginástica laboral aos cavalos terapeutas é conceituada e fundamentada por meio de uma extensa revisão científica, bem como apresenta as aplicações da mesma, baseada nas pesquisas

publicadas no Brasil e internacionalmente. Os profissionais da equoterapia e a comunidade equestre, devem atentar a estes conhecimentos, para não permitir o uso de cavalos nas terapias em condições físicas ruins. Portanto, melhorias na qualidade do atendimento em terapia montada devem começar pela principal ferramenta que proporciona a reabilitação ao paciente, ou seja, o cavalo. Assim, esta publicação tem como objetivo disponibilizar as evidências científicas acerca da realização da ginástica laboral em cavalos terapeutas e seus efeitos sobre a musculatura epaxial, biomecânica do andamento, movimento tridimensional e capacidade de suporte do dorso. 
Sumário

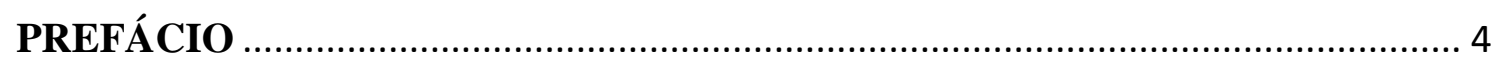

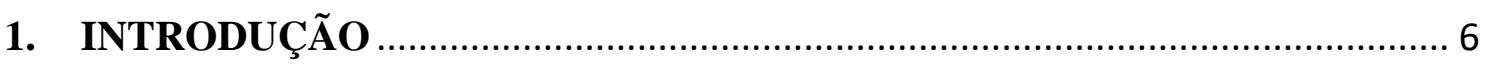

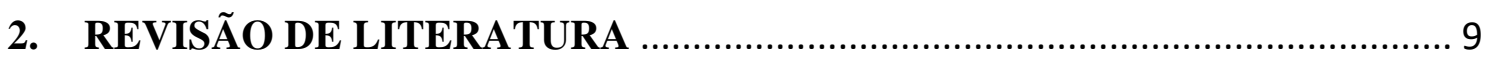

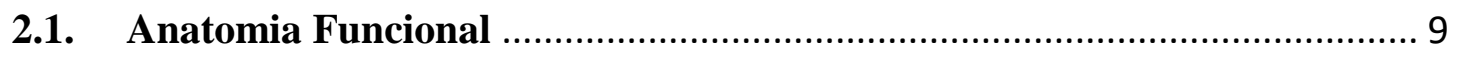

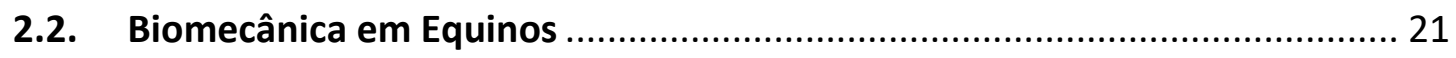

2.3. Exercícios Funcionais e Ginástica Laboral ............................................. 26

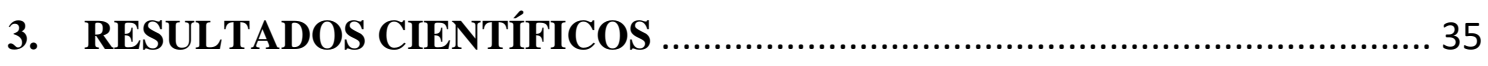

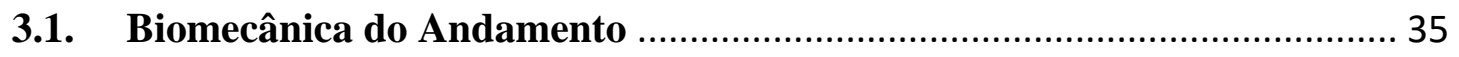

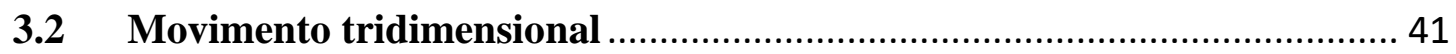

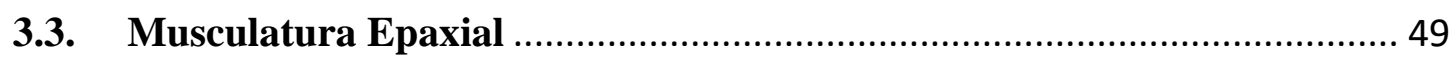

3.4. Capacidade de Suporte do Dorso …............................................................. 54

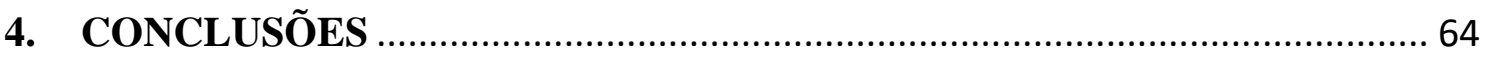

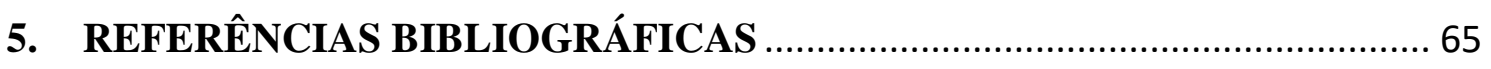

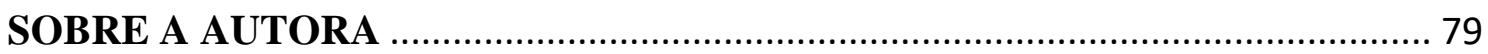




\section{INTRODUÇÃO}

A equoterapia é uma forma de terapia que visa a utilização do cavalo como instrumento de tratamento aos praticantes portadores de deficiências ou de necessidades especiais. A aplicação cinesioterapêutica desta prática se fundamenta no movimento tridimensional realizado pelo animal, durante seu deslocamento no andamento ao passo, que movimenta a pélvis do cavaleiro em padrão similar ao caminhar humano (ENCHEFF et al., 2012).

Sendo assim, a terapia possibilita ganhos efetivos nos domínios físicos, psicológicos, cognitivos e sociais, devido à combinação única do cavalo, andamento e ambiente não clínico, que produz extraordinário esforço em todos os sistemas do corpo do paciente (HAKANSON et al., 2009). No Brasil a equoterapia foi introduzida na década de 70, sendo reconhecida pelo Conselho Federal de Medicina como prática terapêutica em 1997. Segundo a Ande Brasil (Associação Nacional de Equoterapia) existem hoje no país aproximadamente 210 centros de equoterapia, $60 \%$ destes localizados na região Sudeste, realizando 14.000 atendimentos no estado de São Paulo (FERLINI \& CAVALARI, 2010).

A alta demanda e procura crescente da população pela terapia montada tem provocado, nos centros de equoterapia, lentidão nos agendamentos às sessões, bem como a utilização de cavalos em más condições físicas (SILVA et al., 2012). De acordo com Rosa (2006), o cavalo de terapia deve ter extremo potencial de movimento para que o praticante receba tratamento de qualidade, acelerando o processo terapêutico e reabilitativo. Estas características são alcançadas por meio de uma rotina de treinos realizados nos cavalos, para que ocorra manutenção de sua condição física, prevenindo 
à contínua e gradual perda da qualidade dos andamentos. Contudo, isto não é uma realidade nos centros de equoterapia nacional, cujos animais se encontram em estado sedentário.

Adicionalmente, devido à função terapêutica em sessões contínuas, associada à falta de atividade física de suporte, os cavalos de equoterapia podem torna-se susceptíveis a dor muscular (ROSA, 2006; SILVA et al., 2012). Esta ocorrência em cavalos terapeutas pode ter origem semelhante aos trabalhadores humanos, que devido à sobrecarga ou movimentos repetitivos, ocasionam constante tensão tônica dos músculos, dores e com o passar do tempo, a diminuição do vigor estrutural (MACIEL, 1994).

Rosa (2006) relatou que o cavalo durante a sessão está submetido aos desvios posturais do praticante, bem como a desequilíbrios do corpo durante a terapia montada e a diferentes pesos. Neste trabalho identificou-se alteração negativa na qualidade do passo do cavalo nas situações em que os sujeitos apresentavam características especiais como desnível pélvico e excesso de peso corporal.

Sabe-se que quadros de dor lombar nos equinos interferem negativamente na qualidade do passo dos animais (JANURA et al. 2010) e que a mesma está relacionada com detrimento dos músculos epaxiais, principalmente do musculus multifidus (MCGOWAN et al., 2007). Neste sentido, Stubbs et al. (2011), visando diminuir este distúrbio em equinos, desenvolveram rotina de exercício para promover a estabilização das articulações intervertebrais da região toracolombar. Estes pesquisadores verificaram que, a realização dos exercícios baseados na mobilização dinâmica, em cavalos sedentários, resultou em hipertrofia significativa do musculus multifidus, porém não se avaliou seus efeitos sobre os andamentos. 
Vale ressaltar que, a temática sobre a importância da atividade física de cavalos terapeutas sobre o movimento tridimensional e capacidade de suporte é totalmente inédita nas publicações científicas, nacional e internacional. A ginástica laboral aos cavalos terapeutas deve ser estudada para difundir esta tecnologia aos centros de equoterapia do Brasil. A ciência e os profissionais da equoterapia, ignoram este conhecimento e não percebem os malefícios do uso de cavalos em condições físicas ruins sobre a evolução dos pacientes e ao próprio animal.

Portanto, melhorias na qualidade do atendimento em terapia montada devem começar pela principal ferramenta que proporciona a reabilitação ao paciente, ou seja, o cavalo. Neste sentido, esta publicação tem como objetivo disponibilizar as evidências científicas acerca da realização da ginástica laboral em cavalos terapeutas e seus efeitos sobre a musculatura epaxial, biomecânica do andamento, movimento tridimensional e capacidade de suporte do dorso. 


\section{REVISÃO DE LITERATURA}

\subsection{Anatomia Funcional}

O termo esqueleto é aplicado para armação dos ossos que suporta e protege os tecidos moles dos animais. Além de proteger órgãos internos, a coluna contribui com a sustentação do peso, absorção de impacto e promove flexibilidade (HIGGINS e MARTIN, 2012). De acordo com Köning e Liebich (2002), a anatomia é descrita como uma área da morfologia, é uma ciência responsável pelo estudo das formas, abrangendo assuntos como estrutura arquitetônica, formação e atuação funcional simultânea de todos os sistemas que compõem um organismo.

O sistema esquelético é composto por ossos, cartilagens e ligamentos (HODGSON et al., 2014), que desempenham importantes funções de sustentação e conformação do corpo; proteção de órgãos internos e delicados como o pulmão, coração e sistema nervoso central; armazenamento de minerais como cálcio e fósforo. Ainda, produz várias células sanguíneas, determina a conformação, mantem a postura e junto aos músculos realiza a movimentação do corpo (HINCHCLIFF et al., 2008; HIGGINS e MARTIN, 2012).

O esqueleto é representado por 205 ossos e pode ser dividido em esqueleto axial e apendicular. O esqueleto axial é compreendido por 34 ossos no crânio, 54 vértebras na coluna, 36 costelas e um esterno. Já o esqueleto apendicular é compreendido pelos membros torácicos e pélvicos, contendo 40 ossos cada (GETTY, 1986; HENSON, 2009). A coluna do cavalo é constituída por 7 vértebras cervicais (Figura 1), 18 torácicas, 6 lombares, 5 sacrais e de 17 a 21 caudais (BACK e CLAYTON, 2013). 


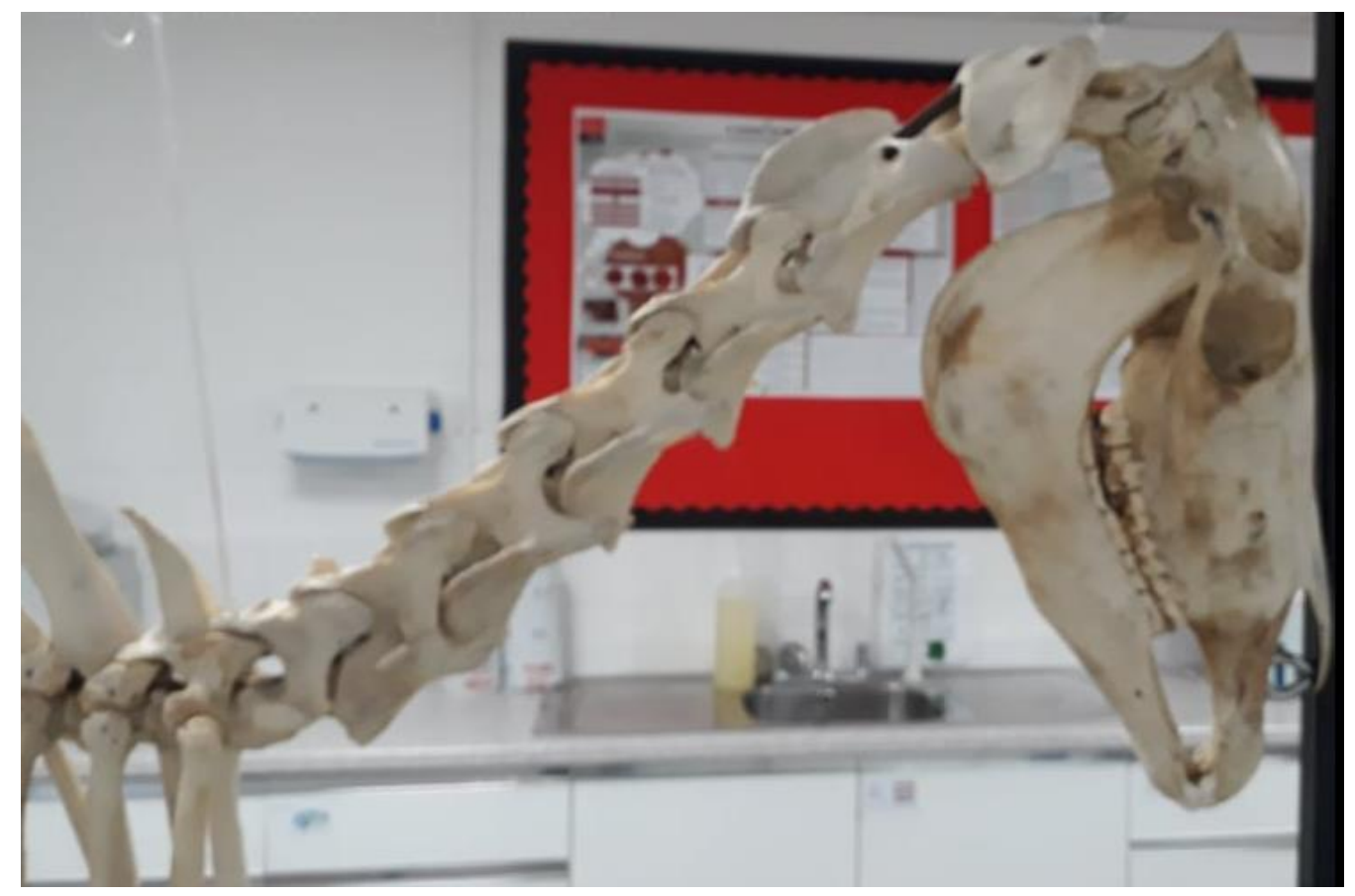

Figura 1. Apresentação das sete vértebras cervicais no equino.

Outras estruturas, como as articulações, são responsáveis pela movimentação junto ao esqueleto. As articulações são formadas quando há a união de um ou mais ossos e são classificadas em fibrosas, cartilaginosas e sinoviais, sendo esta última de maior importância (GETTY, 1986; ALVES, 2008). As articulações permitem o movimento do cavalo além de auxiliar na absorção de impacto.

As principais articulações vertebrais localizadas no segmento axial são dos equinos são a atlanto-occipital (C0-C1), cervical-torácica (C7-T1), lombossacral (L6S1) e sacroíliaca (SI). Estas articulações vertebrais realizam três tipos de movimento: flexão/extensão longitudinal, flexão lateral e rotação axial (OLIVEIRA 2018).

As articulações fibrosas apresentam os ossos conectados por tecido conjuntivo denso e dispõem de pouca mobilidade. As articulações cartilaginosas conectam os ossos através de cartilagem, permitindo poucos movimentos e limitados; e as articulações sinoviais conectam as extremidades ósseas por meio de uma cavidade preenchida por 
fluido (líquido sinovial) e permitem o movimento máximo (MCILWRAITH e VAN WEREEN, 2015).

A articulação sinovial apresenta grande estabilidade e evita que movimentos anormais sejam realizados, reduz os impactos durante as atividades físicas, facilita a mobilidade e torna o atrito entre os ossos praticamente inexistente devido a membrana sinovial que protege as extremidades ósseas. Essa membrana produz o líquido sinovial que apresenta função lubrificante da articulação, e este é responsável por evitar o atrito evitando que haja desgaste da mesma (DYCE et al., 2004).

De acordo com Alves (2008) as articulações sinoviais são classificadas como móveis, permitindo o deslocamento do osso em três dimensões: flexão e extensão longitudinal compreendendo o plano sagital, flexão lateral compreendendo o plano frontal, e os movimentos de rotação. A direção desses movimentos depende da forma das superfícies articulares e as articulações móveis são responsáveis pelo movimento.

Segundo Oliveira (2018) a locomoção ideal dos cavalos ocorre quando não há restrição de movimento nas articulações, ou seja, quando ocorre a perfeita contração e relaxamento dos músculos associados a determinadas articulações, como, por exemplo, a articulação lombo-sacral (L6-S1). Essa articulação é responsável pela inclinação pélvica e colabora com a protração e retração dos membros (CLAYTON, 2016). Portanto, a restrição de movimento contribui para mudanças nas articulações prejudicando sua funcionalidade, promove o desenvolvimento de movimentos assimétricos e, consequentemente, desconforto ao cavalo (LILJEBRINK e BERGH, 2010).

O segmento apendicular, formado pelo aparelho locomotor, é um sistema orgânico complexo constituído pelo sistema esquelético e muscular que, juntos, são 
responsáveis por realizar o trabalho mecânico de movimentação do corpo, estabilidade e suporte (KÖNIG e LIEBICH, 2016). No ponto em que a coluna vertebral se liga com o segmento pélvico encontra-se a articulação sacro-ilíaca, é neste local que ocorre a transferência das forças de propulsão estabelecidas pelo membro posterior para a coluna vertebral (HENSON, 2009).

Alves (2008) relatou que a estabilidade articular, a movimentação dos membros, a postura e a locomoção dependem da ativação dos músculos. Os movimentos dos segmentos corporais, isto é, para frente, para os lados, para trás ou até mesmo movimentos sem alteração de localização, são resultados de contrações musculares coordenados de partes corporais individuais. Estes movimentos dependem de grupos funcionais de músculos, como acontece na locomoção dos cavalos em que os membros são movidos devido à ativação desses músculos (KÖNIG e LIEBICH 2016).

A ação de músculos inseridos em alavancas, permite aos vertebrados a defesa, o ataque, o trabalho mecânico de movimentação, estabilidade e sustentação do corpo (FRANDSON et al., 2016). A musculatura esquelética é responsável pelos movimentos voluntários dos membros, do tronco e da cabeça. Todas as suas variadas funções baseiam-se na contração (encurtamento das fibras) e relaxamento (processo passivo a ausência de contração) (FRANDSON et al., 2011). Sendo o sistema muscular dos equinos constituído por mais de 700 músculos (PILLINER et al., 2009).

De acordo com Reece (2008), os músculos esqueléticos são descritos de acordo com o tipo de movimento realizado, bem como a musculatura atua em pares para realizar o movimento, ou seja, quando um músculo se contrai, por meio de uma ação agonista, o outro se alonga, denominado antagonista, o que ocorre também entre as cadeias musculares flexoras e extensoras (OLIVEIRA, 2019). Desta forma, os músculos 
flexores, localizados no lado do membro no qual a articulação, se dobram para reduzir o ângulo articular. Os extensores quando estiverem localizados no lado do membro no qual a articulação se dobra para aumentar o ângulo articular. Ainda podem ser classificados como adutores aqueles que empurram o membro na direção do plano mediano e abdutores aqueles que empurram o membro para longe do plano mediano.

Os músculos associados ao esqueleto axial podem ser divididos em dois grupos baseados em sua localização em relação aos processos transversos: (1) epaxiais, que se situam dorsalmente e são inervados pelos ramos dorsais dos nervos espinhais, e (2) hipaxiais, ventrais ao processo transverso, que são inervados pelos ramos ventrais dos nervos espinhais. Os músculos epaxiais são responsáveis pela dorsoflexão quando contraídos bilateralmente. A contração unilateral gera uma flexão lateral e contribui para a rotação da coluna vertebral (SISSON, 1986b). Os músculos epaxiais incluem músculo eretor espinhal, formado pelo longuíssimo dorsal (Figura 2), espinhal e iliocostal; músculo multífidus (Figura 3) (HAUSSLER, 1999).

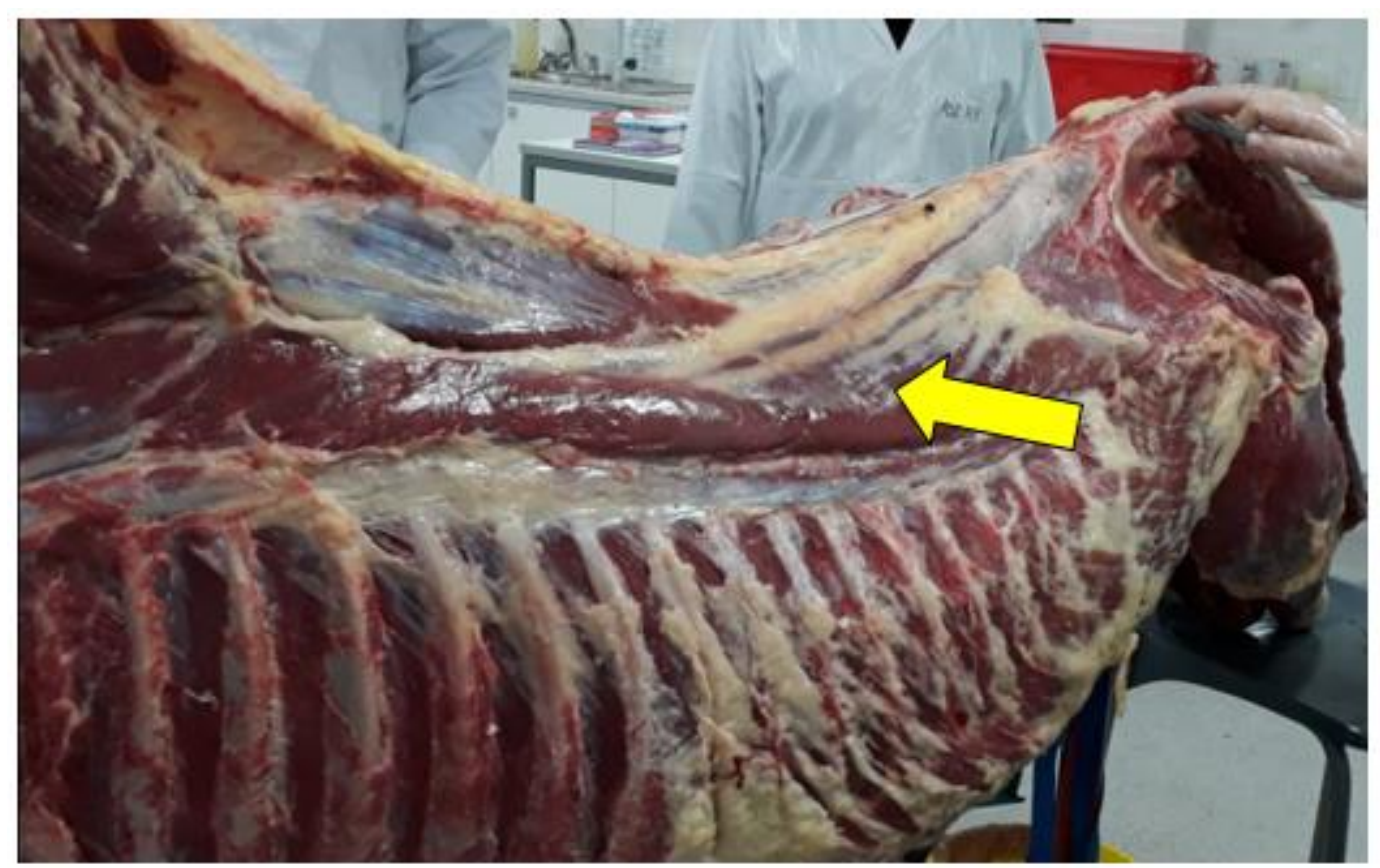

Figura 2. Apresentação do músculo longuíssimo dorsal no equino, em destaque na seta amarela 
Dentro da classificação de músculos epaxiais, o longuíssimo dorsal é um músculo superficial de grande relevância para o equino devido à sua destacada influência na extensão e flexão da coluna vertebral e capacidade de manutenção da postura do animal (D’ANGELIS et al., 2007). Assim como os músculos multífidus desempenham uma função importante de estabilização da coluna ao atuar como a principal fonte de ligação entre suas vértebras, por esta razão também é chamado de músculo estabilizador (ALVES et al., 2007; STUBBS e CLAYTON, 2008; OLIVEIRA, 2019). Com o tempo, estes músculos podem sofrer alterações em seu tamanho, desde a hipertrofia ocasionada pelo treinamento correto e constante, até a atrofia causada por patologias, uso de equipamentos e treinamentos inadequados (TABOR, 2015). O monitoramento muscular, para identificar as adaptações ao treinamento, pode ser acompanhado por meio da avaliação ultrassonográfica, a cada dois meses, na região torácica e lombar (Figura 3).

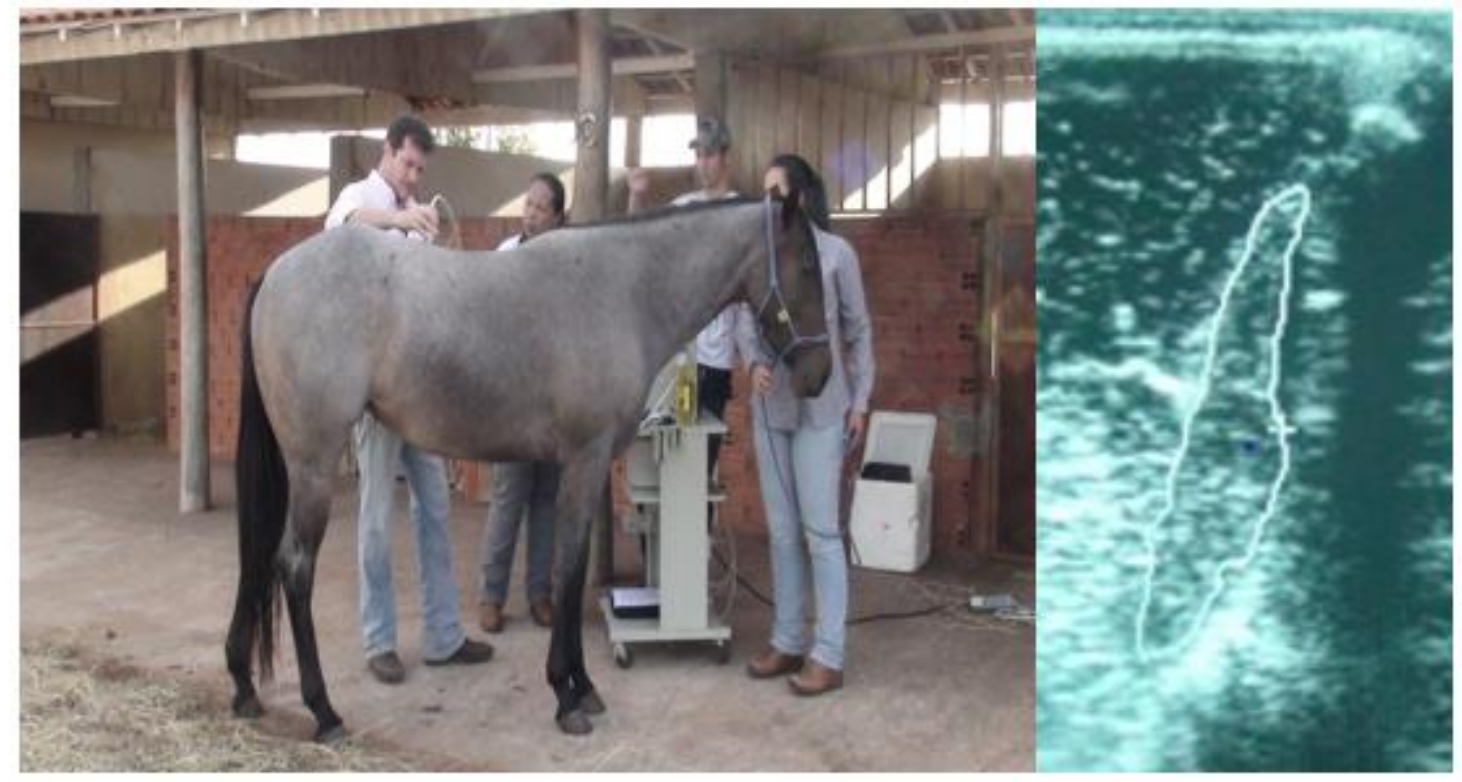

Figura 3. Avaliação ultrassonográfica do musculus multifidus. 
A região toracolombar é responsável por fornecer sustentação ao dorso do cavalo e, além de dar condições ao animal para que suporte melhor o peso do cavaleiro, esta capacidade é alcançada por meio da ação do músculo multífidus em conjunto com os músculos abdominais (Figura 4). Caso isto não ocorra devido ao enfraquecimento destes grupos musculares, o longuíssimo dorsal começa a apresentar espasmos musculares devido ao esforço excessivo que o mesmo passa a realizar (OLIVEIRA, 2018). Ao longo do tempo, o longuíssimo dorsal acaba cedendo à pressão constante do cavaleiro sobre seu dorso e o animal começa a apresentar lordose e desconforto (CLAYTON et al., 2012).

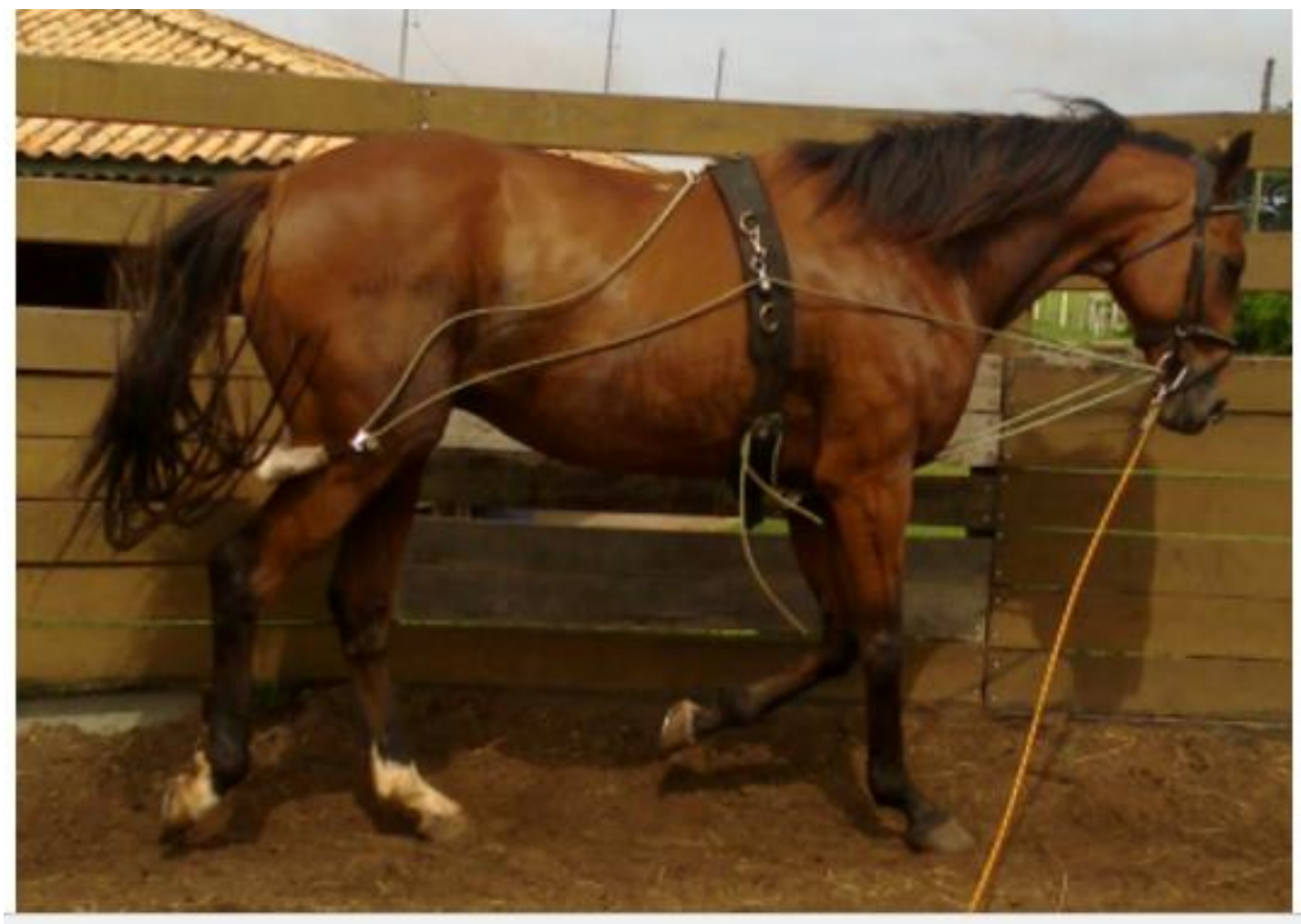

Figura 4. Cavalo apresentando boa postura da coluna, ou seja, boa capacidade de suporte do dorso.

A lordose é caracterizada por uma curvatura exagerada da coluna, que leva a um afundamento significativo da região toracolombar (Figura 5). Esta deformação pode ser primária, quando é congénita ou adquira nos primeiros anos de vida, ou secundária, 
quando provocada por fatores externos. Segundo Gellman (1998) o ajuste incorreto da sela pode causar atrofia muscular na região da cernelha. Porém é notório que todos os equinos de idade avançada apresentam um certo grau de lordose secundária (DENOIX, 1999). A cifose, caracterizada como uma flexão da coluna, assim como a lordose pode ser primária ou secundária (HENSON 2009).

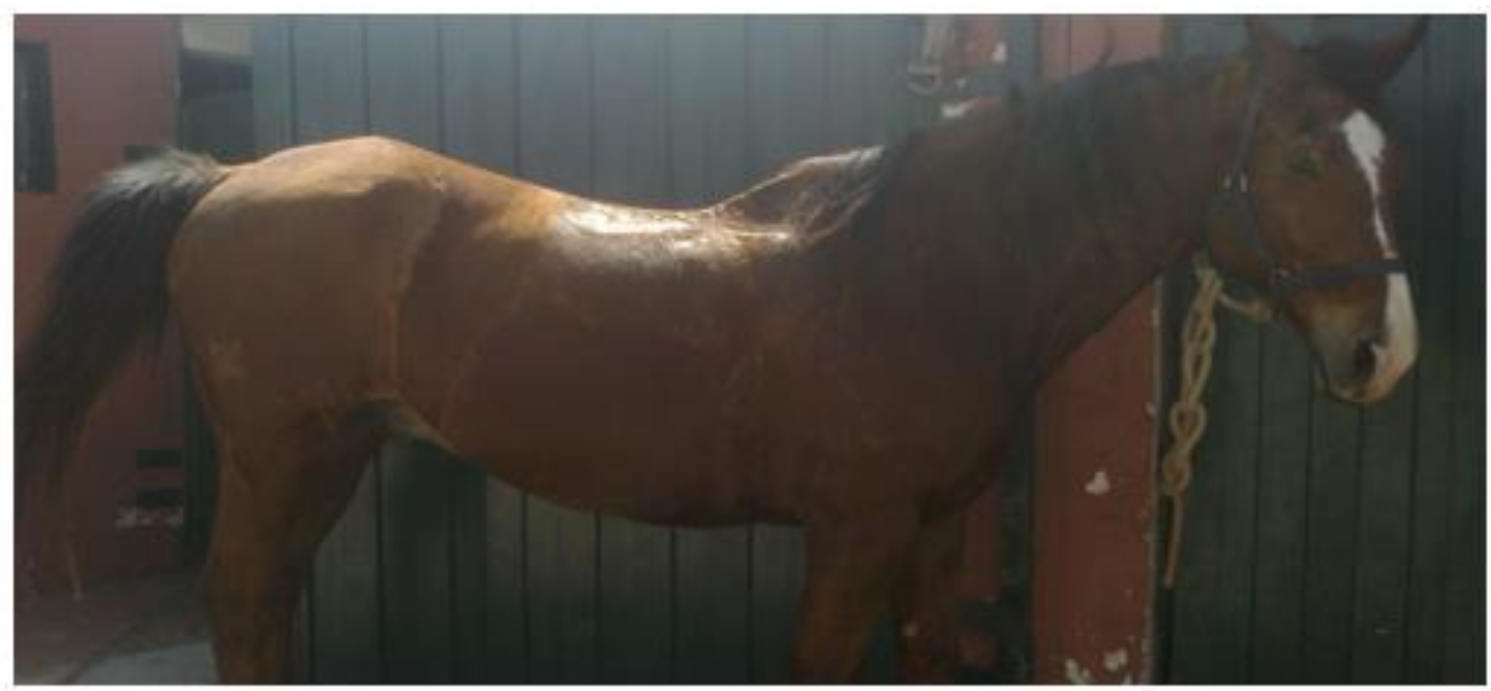

Figura 5. Cavalo apresentando lordose na região toracolombar.

O músculo multifidus, quando atrofiado, interfere na negativamente na estabilização da coluna do cavalo, ou seja, na capacidade de sustentação do dorso do mesmo. Ainda, esta musculatura interfere na habilidade e na forma como o cavalo se movimenta. Deve-se ressaltar que, mesmo quando o animal apresenta redução nos sintomas de dor na região, o músculo multifidus, pode não necessariamente apresentar regeneração e redução na atrofia, a menos que se realizem exercícios de treinamento específico a fim de reativar e fortalecer esse músculo (STUBBS e CLAYTON, 2008).

O sistema muscular dos equinos corresponde a mais de 700 músculos (PILLINER et al., 2009), que são importantes para a sustentação do corpo do cavalo e representam de 40 a $45 \%$ do peso corporal total do animal (HODGSON et al., 2014). Os 
músculos responsáveis pela movimentação do esqueleto equino podem ser divididos em grandes grupos, tais como: músculos do pescoço (Splenius, Rhomboideus, Serratus ventralis cervicis, Sternocephalicus, Braquiocephalicus e Omotransversarius); músculos do cinturão torácico (Serratus Thoracis, Pectoralis, Subclavius e Trapezius); músculos epaxiais (Musculus Multifidus, Longíssimus Dorsi e Iliocostalis); músculos abdominais (Rectus, Transversus e Oblíquus internus e externus) e sublombares (Iliopsoas e Psoas minor) e músculos pélvicos (Gluteus Medius e superficial, Bíceps femoris, Semitendinosus, Semimembranosus, Tensor fascie latae e Gracilis) (STUBBS e CLAYTON, 2008).

Os músculos são formados por fibras musculares responsáveis por transmitir o movimento ao esqueleto ao realizar a contração e por tendões que são responsáveis por unir o tecido muscular ao esqueleto e transferir a força gerada pela contração (ALVES, 2008; KÖNIG e LIEBICH 2016). As fibras musculares ficam agrupadas nos fascículos (pequenos feixes) e são revestidas pelo perimísio. Acima do perimísio encontra-se o endomísio, tecido conjuntivo que reveste o músculo (HINCHCLIFF et al., 2008). Na terminação desse tecido conjuntivo encontram-se os tendões, que fazem a ligação do músculo ao esqueleto (DYCE et al., 2004).

Os equinos apresentam, de forma geral, dois tipos de fibras musculares esqueléticas: fibras do tipo I (vermelhas) e fibras do tipo II (brancas). As fibras vermelhas são consideradas como de contração lenta e dependentes do metabolismo aeróbico para produção de energia, já as fibras brancas são classificadas como de contração rápida e utilizam o metabolismo glicolítico anaeróbico para síntese de ATP de forma mais rápida (DYCE, 2004). Os equinos possuem ainda outros tipos de fibras musculares, como aquelas do tipo IIA e IIX, que possuem metabolismo intermediário quando comparadas às do tipo I e II (DYCE, 2004; REGATIERI e MOTA 2012). 
A contração muscular ocorre pelo encurtamento das miofibrilas em que os filamentos de actina deslizam sobre os de miosina. Esse processo tem início com a chegada de um impulso nervoso até a fibra muscular na região da placa motora, causando a despolarização das células e fazendo com que o cálcio ionizado armazenado no retículo sarcoplasmático das fibras musculares seja liberado nos túbulos transversos. O cálcio ionizado, ao atingir a actina, desbloqueia seus sítios de ligação e permite a ligação entre a actina e miosina. Neste momento, na presença de ATP, ocorre o encurtamento do sarcômero e a contração muscular propriamente dita (KLEIN, 2014).

Os músculos são nomeados de acordo com sua função ou de acordo com os lugares que estão localizados, e podem ser apresentados em dois sistemas: superficiais e profundos. Os músculos superficiais estão logo abaixo da pele e caracterizam-se em serem mobilizadores, enquanto que os profundos encontram-se sob os músculos superficiais, ligados as articulações e parte óssea, possuindo a função de sustentação (PILLINER et al., 2009; OLIVEIRA, 2018).

O fortalecimento dos músculos do pescoço é importante para que a cabeça seja capaz de se sustentar ao alto e permitir que o cavalo tenha um melhor equilíbrio e distribuição de peso. O trabalho em conjunto da cabeça e pescoço permite que o animal altere com maior facilidade o seu centro de gravidade. Quando a cabeça e o pescoço se abaixam, o centro de gravidade se move para frente porque mais peso é transferido aos membros torácicos e, ao contrário disso, quando a cabeça e o pescoço se levantam o centro de gravidade recua e mais peso é deslocado aos membros pélvicos (PILLINER et al., 2009).

Ao considerar os músculos epaxiais, destaca-se o Longissimus Dorsi (LD), músculo superficial de grande importância ao equino devido à sua destacada influência 
na extensão e flexão da coluna vertebral e capacidade de manutenção da postura do animal (D’ANGELIS et al., 2007). O LD é o maior músculo presente no corpo do equino, se origina dos processos espinhosos do sacro, vértebras lombares e torácicas e asa do ílio. Em conjunto com o Iliocostalis, o LD é capaz ainda de promover a flexão lateral do dorso. Dentre os músculos epaxiais, aquele classificado como profundo é o Musculus Multifidus (MM). O mesmo desempenha uma função importante de estabilização da coluna ao atuar como a principal fonte de ligação entre suas vértebras, por este motivo é também chamado de músculo estabilizador (ALVES et al., 2007; STUBBS e CLAYTON, 2008; OLIVEIRA, 2018).

Assim como em humanos, uma das principais causas de lombalgias em equinos é a atrofia do MM. Hides et al. (2008) estudaram a lombalgia em humanos ao comparar MM de pacientes com ou sem histórico de dor lombar crônica, os autores constataram que os pacientes com lombalgia possuíam a área de seção transversal (AST) do MM significativamente menor quando comparados aos pacientes sem lombalgia. Além disso, verificaram ainda que os pacientes com lombalgia apresentavam assimetria lateral no músculo, com distribuição de dor unilateral ipsilateral ao de menor tamanho.

O MM, quando atrofiado, interfere na estabilização da coluna do cavalo e na habilidade de seus movimentos e, mesmo que o animal apresente redução nos sintomas de dor na região, este músculo pode não necessariamente apresentar regeneração e redução na atrofia, a menos que se realizem exercícios de treinamento específico a fim de reativar e fortalecer esse músculo (STUBBS e CLAYTON, 2008). Além da dor, um dos sinais de atrofia do MM, é a presença de espasmos musculares palpáveis no LD devido ao aumento de sua tensão ao tentar compensar a inativação do MM (CLAYTON, 2016). 
Oliveira (2019) relatou a importância do MM em melhorar a qualidade do desempenho de equinos atletas, principalmente em movimentos que necessitam de grande transferência de força dos membros pélvicos para a coluna, movimentos estes, naturalmente desestabilizadores. Segundo Secani \& Lega (2009), a maior parte das dores que acometem o dorso de equinos atletas e de trabalho são consequências, muitas vezes, da falta de preparo físico e/ou atividade física constante e intensa, ultrapassando o limite do corpo do animal. Os autores afirmam ainda que a ocorrência de dores por contraturas e tensões será menor quanto maior for a resistência e trabalho coordenado entre as fibras musculares ativadas.

O desenvolvimento muscular na região da garupa é importante para melhorar a locomoção do cavalo através do aumento da protração dos membros pélvicos e uma maior flexibilidade. De acordo com Hill e Crook (2010), a manipulação dos músculos caudais (glúteo superficial, semitendinoso, semimembranoso e bíceps femoral) aumenta a protração passiva dos membros pélvicos, e esses associados com uma maior retração dos membros torácicos promovem uma melhoria na flexibilidade e na flexão lateral do corpo do cavalo.

Os membros torácicos apresentam função de controlar a impulsão da projeção do cavalo para frente e age como amortecedores dando uma maior estabilidade na postura. Enquanto os membros pélvicos são propulsores e responsáveis por mover o cavalo para frente geralmente em grande velocidade (PILLINER et al., 2009; BIKNEVICIUS et al., 2004). Se esses membros apresentam um alinhamento adequado, consequentemente o animal vai apresentar um maior equilíbrio e uma maior agilidade na locomoção. 
Vale ressaltar que, com o tempo os músculos podem sofrer alterações em seu tamanho, desde a hipertrofia ocasionada pelo treinamento correto e constante, até a atrofia causada por patologias, uso de equipamentos e treinamentos inadequados (TABOR, 2015). Portanto, independente de modalidade esportiva ou de função (equoterapia, patrulhamento, cavalgada ou lazer), os cavalos podem se beneficiar de um programa de fortalecimento e de alongamento à musculatura de sustentação na rotina física destes animais. Com certeza, isto colaborá com a longevidade do cavalo terapeuta, melhorando sua qualidade de vida e bem-estar.

\subsection{Biomecânica em Equinos}

Biomecânica é a ciência que estuda os movimentos de um corpo vivo bem como as estruturas envolvidas na execução do movimento (músculos, ossos, tendões e ligamentos). O primeiro estudo relacionado à biomecânica de equinos foi realizado em 1887 pelo fotógrafo inglês Muybridge, responsável pelo primeiro registro quadro a quadro do galope de um cavalo de corrida (MUYBRIDGE, 2012). Avaliar a maneira com que um equino se movimenta fornece importantes dados aos pesquisadores, treinadores e profissionais da área a respeito dos pontos positivos e problemas que um animal possui, estas informações são essenciais para melhorar o desempenho atlético de animais atletas e de função (HOBBS et al., 2010).

De acordo com Gomez Alvarez (2007), a locomoção de um equino poderia ser avaliada por um observador, porém é uma análise muito subjetiva e que não permite avaliações precisas de determinadas regiões do corpo do animal, como por exemplo do dorso, cuja movimentação pode apresentar alterações muito sutis imperceptíveis por observação visual, sendo assim, a análise biomecânica permite um exame detalhado da postura e locomoção equina. 
Assim, com o desenvolvimento de novas tecnologias e com o advento do computador, câmeras digitais de alta resolução e filmagens utilizando a técnica slowmotion, foi possível dar início e tornar extremamente preciso e complexo os estudos referentes à biomecânica de humanos e animais atletas, evidenciando determinados aspectos que, por observação visual, não poderiam ser notados na inspeção clínica. Neste sentido, Pesquisadores têm utilizado sistemas de captura de movimento em 3-D, para explorar os movimentos de flexão-extensão, curvatura lateral e rotação axial da coluna vertebral de cavalos. Estes parâmetros são responsáveis pelo movimento tridimensional transmitido aos praticantes, sendo estas mensurações de grande importância nos estudos de cavalos terapeutas (HOBBS et al., 2010).

A análise biomecânica pode ser subdividida em cinética, que corresponde ao estudo das forças aplicadas ao corpo responsáveis por gerar e alterar o movimento; e cinemática, que descreve os movimentos (CLAYTON, 2004; BACK e CLAYTON, 2013). Os movimentos são descritos por variáveis cinemáticas relacionadas com o tempo, deslocamento, aceleração e velocidade HINCHCLIFF et al., 2008). A análise cinemática quantifica variáveis temporais, linear e angular, que descrevem os movimentos do corpo e de articulações (CLAYTON \& SCHAMHARDT, 2001).

Segundo Hinchcliff et al. (2008) a análise cinemática é baseada na relação entre posição do animal versus tempo, que pode ser obtida por meio de análises videográficas, bidimensionais (Figura 6) ou tridimensionais, com auxílio de computador e programas de análises de imagens. Esta análise se baseia no registro de imagens e avaliação de pontos marcados no corpo do animal, permitindo a mensuração de diferentes variáveis durante o movimento, tais como: angulação das articulações, distâncias vertical e horizontal do centro de massa, velocidade e aceleração (BOBBERT et al., 2005; MIYASHIRO, 2012). 


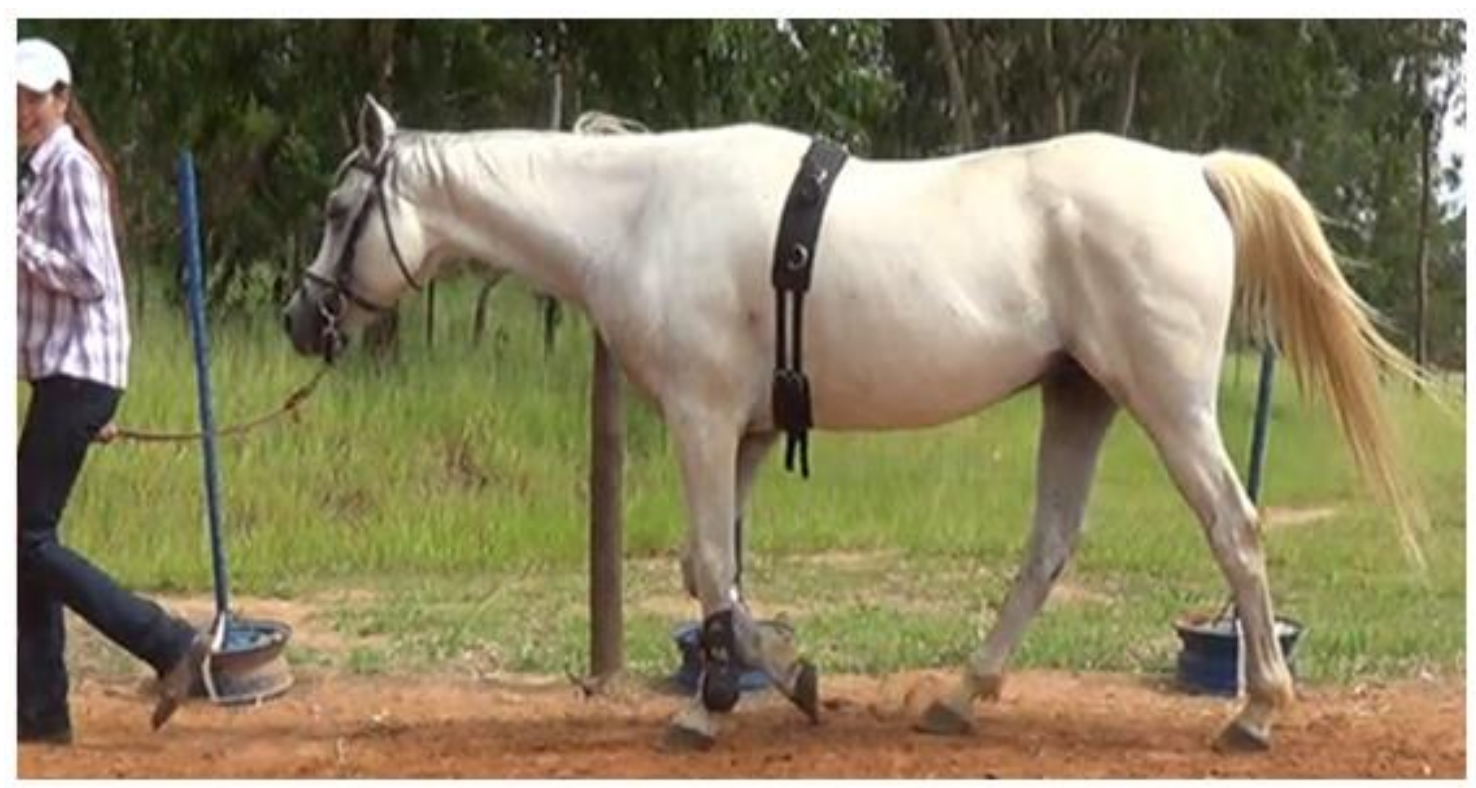

Figura 6. Avaliação cinemática bidimensional por videografia.

Bystrom et al. (2009) realizaram a avaliação cinemática com o objetivo de descrever os movimentos da sela e cavaleiro em sete equinos de adestramento de alto nível enquanto realizavam trote em uma esteira. Esses autores verificaram que o movimento da sela e cavaleiro está relacionado com os movimentos do cavalo e que o movimento de sela também pode ser influenciado pelo cavaleiro. Portanto, com esse estudo é possível compreender que conhecer os movimentos da sela e do cavaleiro são importantes para prevenir tanto lesões ortopédicas quanto musculares.

A avaliação biomecânica pode ser realizada também para avaliar a velocidade, ritmo, regularidade, simetria, amplitude e a suspensão de qualquer andamento do equino, seja ele o passo, trote ou galope. A regularidade e simetria são importantes índices de claudicação em cavalos (LÓPEZ-SANROMÁN et al., 2012; DYSON et al., 2019), Assim, espera-se que um bom andamento possua boa regularidade e simetria, realizados com elasticidade, mantendo-se a frequência de passada (BURLA et al., 2014). Ainda, a velocidade de deslocamento é um importante fator no aumento de força gerado pelo cavalo, impactando, consequentemente, a análise cinética também (de COCQ et al., 2006; de COCQ et al., 2009). 
Durante o deslocamento o cavalo pode realizar três tipos de andamentos, o passo, trote e galope, sendo este último apresentando maior velocidade. O passo é definido com um movimento de quatro tempos, em que o animal movimenta apenas um dos membros de cada vez. Já o trote é um movimento de dois tempos onde ocorre alternância entre as diagonais, esquerda e direita, separadamente por um momento em suspensão no ar. O galope pode ser classificado como um andamento de três tempos, apresentando uma sequência de apoios sobre um membro anterior, outra diagonal e finalizando com apoio do membro posterior, seguido por um momento em suspensão (CLAYTON et al., 2012).

$\mathrm{Na}$ locomoção do cavalo, os membros passam por ciclos de movimentos repetitivos chamados de passadas (PILLINER et al., 2009). O comprimento da passada é medido pela distância percorrida do mesmo membro ao fixar no solo consecutivamente (PILLINER et al., 2009; BACK e CLAYTON, 2013). DVOŘÁKOVÁ et al. (2009) realizaram um estudo para avaliar os movimentos de dois equinos durante cinco semanas de hipoterapia e observaram um comprimento de passada ao passo de $169 \mathrm{~cm}$ e $189 \mathrm{~cm}$. Oliveira et al. (2015), ao avaliarem o comprimento da passada ao passo durante 90 dias, observaram que os equinos submetidos a ginástica laboral $(146,00$ e 156,67 cm) apresentaram valores superiores no comprimento da passada quando comparado aos equinos submetidos a exercícios de mobilização dinâmica $(137,33$ e 139,67 cm) e animais sedentários (126,00 e 126,67 cm), na avaliação inicial e final respectivamente.

A distância da passada (DP) é a medida entre o casco do membro torácico e o membro pélvico ipsilateral (PILLINER et al., 2009). Assim, esta variável relaciona-se com a amplitude do passo e quando o casco do membro pélvico aterrissa a frente do local onde o casco torácico ipsilateral estava anteriormente apoiado no solo, é chamado 
de ultrapegada ou transpistamento. Cavalos com ultrapegada caracterizam-se por apresentar um passo longo, amplo, grande e com frequência baixa, gerando valores positivos do parâmetro DP (BACK e CLAYTON, 2013).

O animal que apresenta a sobrepegada ou sobrepistamento, são geradores de valores de DP iguais a zero, bem como apresenta o casco do membro pélvico aterrissando exatamente no local onde o casco torácico estava anteriormente. O cavalo que realiza a sobrepegada apresenta uma amplitude e frequência média (CHIROLLI et al., 2015). Ao contrário quando o casco do membro pélvico aterrissa atrás do local onde estava anteriormente o casco do membro torácico, é chamado de retropegada ou antepistamento e são geradores de valores de DP negativos. Realiza um passo curto e como consequência a amplitude é pequena e a frequência do passo é alta (OLIVEIRA et al., 2015).

Para cavaleiros com desabilidades motoras, apresentando alteração na marcha, a qualidade do passo do cavalo e, consequentemente, a biomecânica do movimento tridimensional no dorso do mesmo, tornam-se imprescindíveis para melhorar a reabilitação do praticante nos programas de hipoterapia (ARRUDA et al., 2006). JOHNSTON et al. (2004), encontraram que a idade e o tempo de uso do cavalo influenciam a cinemática do dorso, provavelmente devido ao encurtamento muscular, aumentando a incidência de retropegada.

Ainda, em estudo do tipo observativo, ROSA (2006), avaliou os efeitos do peso corporal e do desvio de pélvis de indivíduos montados sobre a biomecânica de um cavalo. Concluiu-se que cavaleiros mais pesados e com desvio de pélvis interferiram negativamente na qualidade do passo do animal. Contudo, não foi avaliado o efeito do cavaleiro sobre a dinâmica do dorso, bem como a resposta do praticante ao deslocamento provocado pelo cavalo em movimento. 
É notório o conhecimento de que a qualidade do passo do cavalo de terapia, possui grande importância para que o mesmo possa realizar com eficiência o movimento tridimensional (SVOBODA et al., 2011). Desta forma, o alongamento do dorso (CLAYTON, 2004) e fortalecimento da musculatura abdominal e pélvica (HIGGINS, 2009b) são pré-requisitos fundamentais para a boa movimentação tridimensional, que são negligenciados pelos pesquisadores que avaliam este tema.

Corroborativamente, Dvorakova et al. (2009), salientam a necessidade da ação conjunta das musculaturas dorsal e ventral do cavalo para o adequado movimento tridimensional. Assim, o cavalo de terapia deve ter um extremo potencial de movimento para que o praticante receba um tratamento de qualidade, acelerando o processo terapêutico e reabilitativo. Estas características são alcançadas por meio de uma rotina de treinos realizados nos cavalos para que ocorra a manutenção de sua condição física, prevenindo a contínua e gradual perda da qualidade dos andamentos.

\subsection{Exercícios Funcionais e Ginástica Laboral}

Nos últimos anos, diferentes técnicas de terapia manual realizadas em humanos para tratamento de distúrbios musculoesqueléticos passaram a ser utilizadas também em equinos. Essas técnicas, como os exercícios funcionais, estão ganhando destaque na rotina dos cavalos (OLIVEIRA, 2018). Em equinos ainda são poucos os estudos que evidenciam os efeitos da terapia manual, no entanto, algumas pesquisas já demonstram que a terapia por meio da mobilização da coluna vertebral promove uma hipertonicidade muscular, aumento da amplitude de movimento articular e redução de dor (HAUSSLER, 2009).

O treinamento funcional terapêutico é uma das diversas técnicas que existe dentre os tratamentos fisioterapêuticos aplicados às desordens sensoriais e motoras do 
sistema musculoesquelético provocadas pelo esporte ou trabalho (MCGOWAN et al., 2007a). Entretanto, previamente à aplicação dos exercícios funcionais é necessário que se determine de forma precisa as desordens musculoesqueléticas que os animais possuem. Esta avaliação é essencial para gerenciar qual tipo de tratamento será aplicado ao animal e, por fim, estabelecer quais exercícios funcionais devem ser aplicados, com a intenção de restaurar os movimentos para a melhoria funcional e reabilitação de desempenho (GOFF, 2009).

Diversos estudos realizados com seres humanos comprovaram que há uma redução significativa das dores nas costas após realização de exercícios funcionais que atuam principalmente sobre o MM, promovendo a estabilidade da coluna (TABOR, 2015). Este efeito dos exercícios funcionais sobre o MM também já foi comprovado na espécie equina (STUBBS et al., 2011; OLIVEIRA et al., 2015; TABOR, 2015).

Segundo Allen et al. (2010), para constatar a ocorrência de lombalgia em equinos os sintomas que podem ser observados são claudicação, atrofia muscular, assimetria muscular, alto grau de sensibilidade das vértebras da região toracolombar. Ainda, pode-se visualizar desequilíbrio, assimetria no andamento e qualquer sinal de desconforto no animal em movimento em linha reta e em círculo sobre uma superfície plana.

Outra forma de constatar a presença de alguma desordem musculoesquelética é através de testes de restrição de movimento. Segundo Oliveira (2018), para identificar as principais restrições de movimento e a funcionalidade dos equinos deve-se realizar uma avaliação funcional do animal. Para isso é necessário observar a postura do animal em estação, avaliar a estrutura anatômica para identificação de alterações ósseas, quantificar a força muscular para verificar se determinado músculo apresenta força 
considerada "normal". Também são avaliados a elasticidade muscular por meio de teste de amplitude de movimento, determina-se a flexibilidade de forma a identificar déficits dos movimentos articulares, bem como é avaliado a estabilidade articular para identificar a capacidade de estabilização da articulação sacro-ilíaca.

Os exercícios funcionais podem reduzir as restrições de movimento em qualquer segmento da coluna ao promover maior flexibilidade, redução da tensão e relaxamento dos músculos, melhora da coordenação motora e fortalecimento muscular (OLIVEIRA, 2018). Contudo, estes exercícios devem ser sempre realizados após aquecimento prévio do animal, já que o aquecimento aumenta a temperatura corpórea e, consequentemente, desencadeia um relaxamento do musculoesquelético e aumento da flexibilidade muscular (GUIRRO et al., 2012).

As restrições de movimento podem ser consequência da má conformação do animal, treinamento inadequado e utilização de equipamentos de maneira errada. Segundo Oliveira (2018), as restrições podem ocorrer em qualquer articulação e/ou intersegmento vertebral do corpo do animal, e podem ou não estar acompanhadas de sinais de dor ou desconforto. Segundo o autor, as principais restrições de movimento encontradas em equinos atletas e de trabalho compreendem as articulações atlantoocciptal/atlanto-axial (C0-C2), articulação cervical-torácica (C7-T1), segmentos intervertebrais da T3-T11, articulação toracolombar, articulações do lombo-sacral e sacro-ilíaca e o complexo da espádua.

Os principais problemas decorrentes destas restrições são diversos, os mais comumente observados são a fraca capacidade de sustentação do dorso, distribuição desigual do peso do animal entre os membros, grande tensão muscular, ausência de flexibilidade, atrofia de diversos músculos, capacidade de propulsão e amplitude de 
passada reduzida (CLAYTON, 2004; OLIVEIRA et al., 2014; OLIVEIRA, 2018). Para estas desordens de função são recomendados os exercícios funcionais para amenizar, ou até mesmo acabar com as restrições musculares, como fortalecimento da musculatura epaxial, fortalecimento do cinturão torácico, alongamentos e fortalecimento da musculatura pélvica (STUBBS e CLAYTON, 2008; OLIVEIRA, 2019).

Outros exercícios funcionais, como os de mobilização dinâmica, aumentam a amplitude do movimento articular e fortalece a musculatura no qual o exercício é associado (CLAYTON et al., 2012). A mobilização dinâmica ocorre quando o animal é guiado com o auxílio de um petisco e exercita sua musculatura por meio de flexões longitudinais e laterais de pescoço, dorso e pélvis. Eles podem ser divididos em: extensão cervical, flexão lateral da cabeça, flexão longitudinal da cabeça e pescoço e flexão lateral do pescoço e dorso (HAUSSLER, 2009; CLAYTON, 2016).

Stubbs et al. (2011) avaliaram o efeito dos exercícios de mobilização dinâmica (extensão cervical, flexão cervical longitudinal e flexão cervical lateral) durante 90 dias sobre o MM em seis regiões específicas da coluna de oito equinos. Os autores observaram um aumento significativo no tamanho do $\mathrm{MM}$ em todas as regiões avaliadas, além do estabelecimento de simetria muscular entre os lados esquerdo e direito do corpo dos animais.

O mesmo foi observado por Oliveira et al. (2015) quando avaliaram o efeito dos exercícios de mobilização dinâmica (extensão cervical, flexão cervical longitudinal e flexão cervical lateral) e ginástica laboral (extensão cervical, flexão cervical longitudinal, flexão cervical lateral, flexão lateral da pélvis, recuo, caminhada sobre obstáculos e spinning) em equinos. Os autores verificaram que os grupos submetidos a 
exercícios de mobilização dinâmica apresentaram hipertrofia do MM, e um maior tamanho desse músculo comparado aos animais sedentários.

Os exercícios de mobilização reflexiva promovem uma resposta neuroreflexiva a um estímulo manual aplicado em determinada área do corpo do animal, que promove de forma muito eficiente do fortalecimento da musculatura de sustentação (OLIVEIRA, 2018). A resposta do estímulo é a flexão e/ou flexão lateral de articulações intervertebrais específicas através da ativação de músculo mobilizadores das regiões cervical, torácica e lombar por meio de exercícios de levantamento do esterno, cernelha e tórax, flexão unilateral da pélvis e flexão bilateral da pélvis (GOFF, 2009; CLAYTON, 2016).

$\mathrm{O}$ alongamento passivo corresponde ao elongamento das fibras musculares e ligamentos promovendo aumento da flexibilidade e amplitude de movimento do pescoço, dorso ou membros e reduzindo o risco de lesões de músculos e tendões (KANEPS, 2016; OLIVEIRA 2019). O alongamento pode ser passivo ou ativo: o passivo consiste na aplicação de força a um determinado segmento do corpo ou membro a fim de alongar os músculos relaxados além de seus comprimentos normais de descanso (HAUSSLER, 2010). Enquanto que o alongamento ativo promove o alongamento no animal por meio do uso de seus próprios movimentos, geralmente utiliza-se cenoura como petiscos para indução de alongamentos do pescoço e tronco a fim de estimular o animal a aumentar sua flexão e/ou extensão (STUBBS e CLAYTON, 2008). Os exercícios de alongamento passivo usualmente aplicado são a protração, retração e adução dos membros torácicos e pélvicos (GOFF, 2009; HAUSSLER, 2016).

Os exercícios de desequilíbrio dinâmico têm como objetivo melhorar o equilíbrio, estabilidade e coordenação motora por meio de exercícios que induzem a 
contração muscular do animal em resposta ao deslocamento de seu centro de gravidade durante um movimento. Isso pode ser obtido pela aplicação de exercícios de recuo, caminhada sobre obstáculos e spinning (OLIVEIRA, 2018).

A utilização de técnicas de fortalecimento muscular e alongamentos são práticas essenciais que irão trazer incontáveis benefícios ao animal, maximizando seu desempenho atlético e sua capacidade de realizar determinada função, além de poder proporcionar ainda um maior grau de bem-estar ao animal. Isto ocorre devido ao exercício de alongamento que visa à manutenção dos níveis de elasticidades muscular, obtendo movimentação com amplitude normal e com mínimo de restrição física possível. Da mesma forma, as séries de fortalecimento muscular objetivam oferecer sustentação às estruturas músculo-esqueléticas, diminuindo os processos dolorosos no indivíduo (DANTAS, 2005). Neste sentido, a ginástica laboral, por ser formada por exercícios de alongamento e de fortalecimento muscular, pode ser utilizada com a finalidade de melhorar a função do cavalo como ferramenta de reabilitação aos praticantes de equoterapia, sem prejuízos a qualidade de vida do animal (OLIVEIRA et al., 2015).

Oliveira et al. (2015) objetivaram avaliar o efeito da ginástica laboral em cavalos de terapia sobre a biomecânica do passo e desenvolvimento da musculatura epaxial. A ginástica laboral para os cavalos de equoterapia foi composta por exercícios de mobilização dinâmica, de fortalecimento muscular ao abdômen e de estabilização da pélvis, realizada três vezes por semana, durante três meses. Nesta ginástica laboral, a série de exercícios de mobilização dinâmica foi constituída por três exercícios de flexão cervical longitudinal, cabeça entre os cascos torácicos, cabeça entre carpos e cabeça no manúbrio, (Figura 7), um exercício de extensão cervical (Figura 8) e três exercícios de 
flexão cervical lateral (direita e esquerda), cabeça na espádua, cabeça na patela e cabeça no jarrete, (Figura 9), totalizando em dez mobilizações.

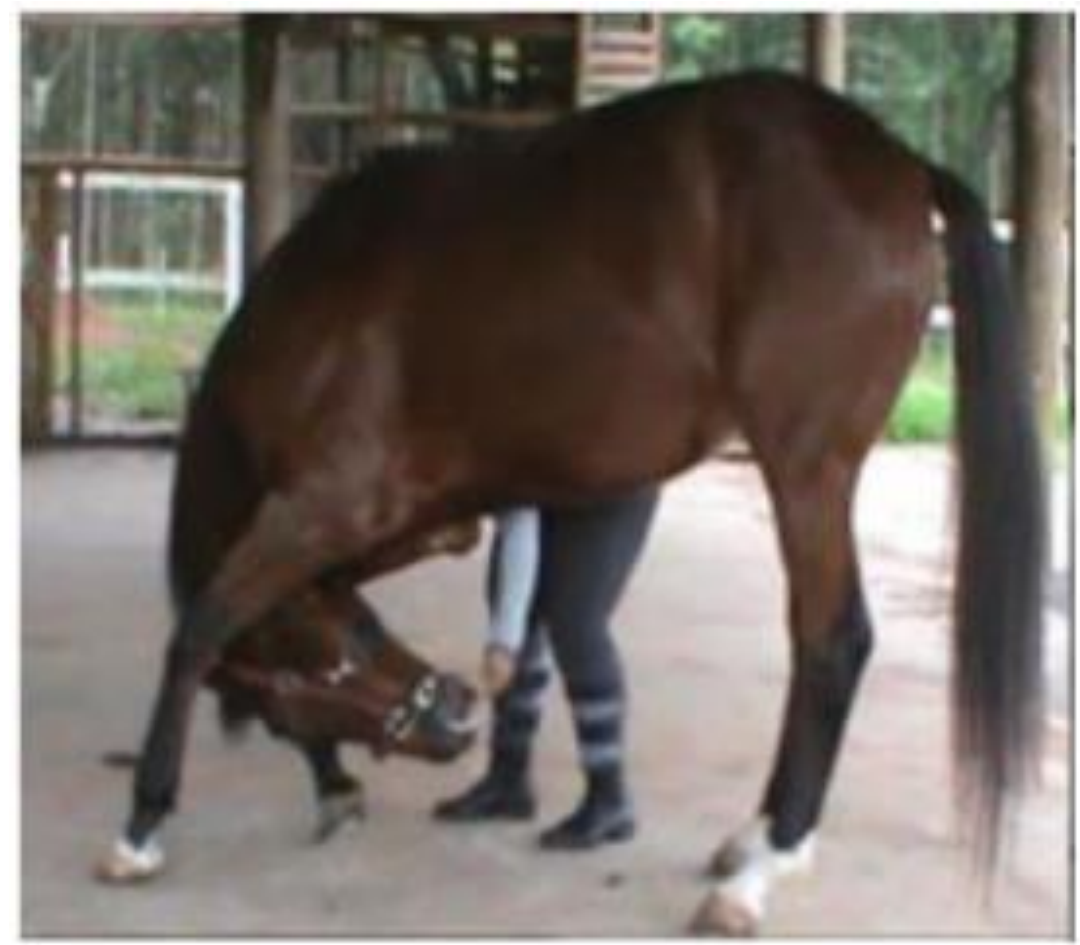

Figura 7. Flexão cervical longitudinal, com a cabeça entre carpos.

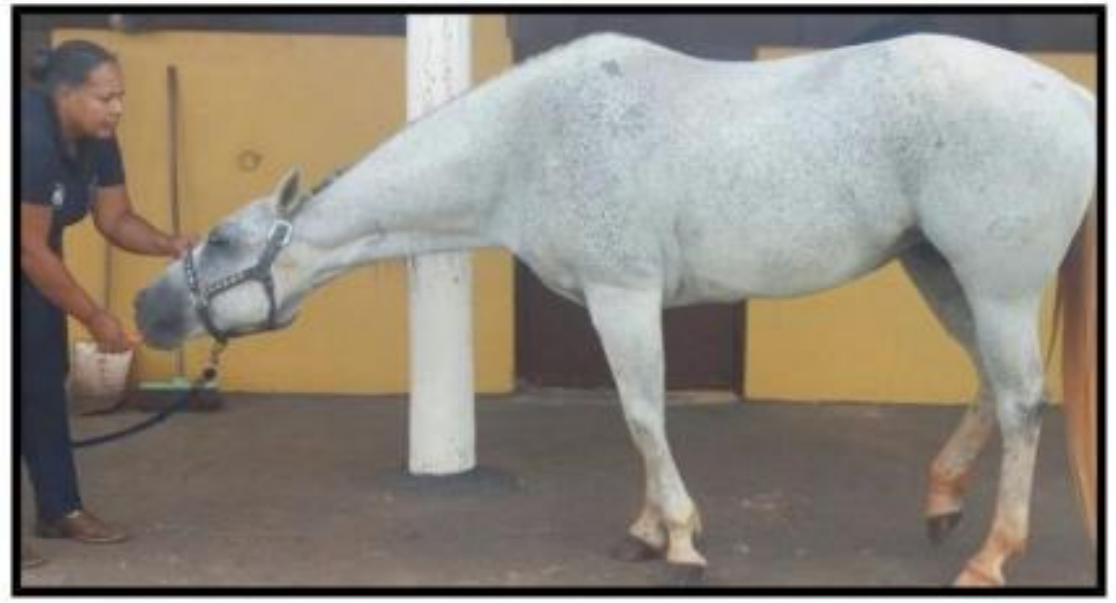

Figura 8. Extensão cervical 


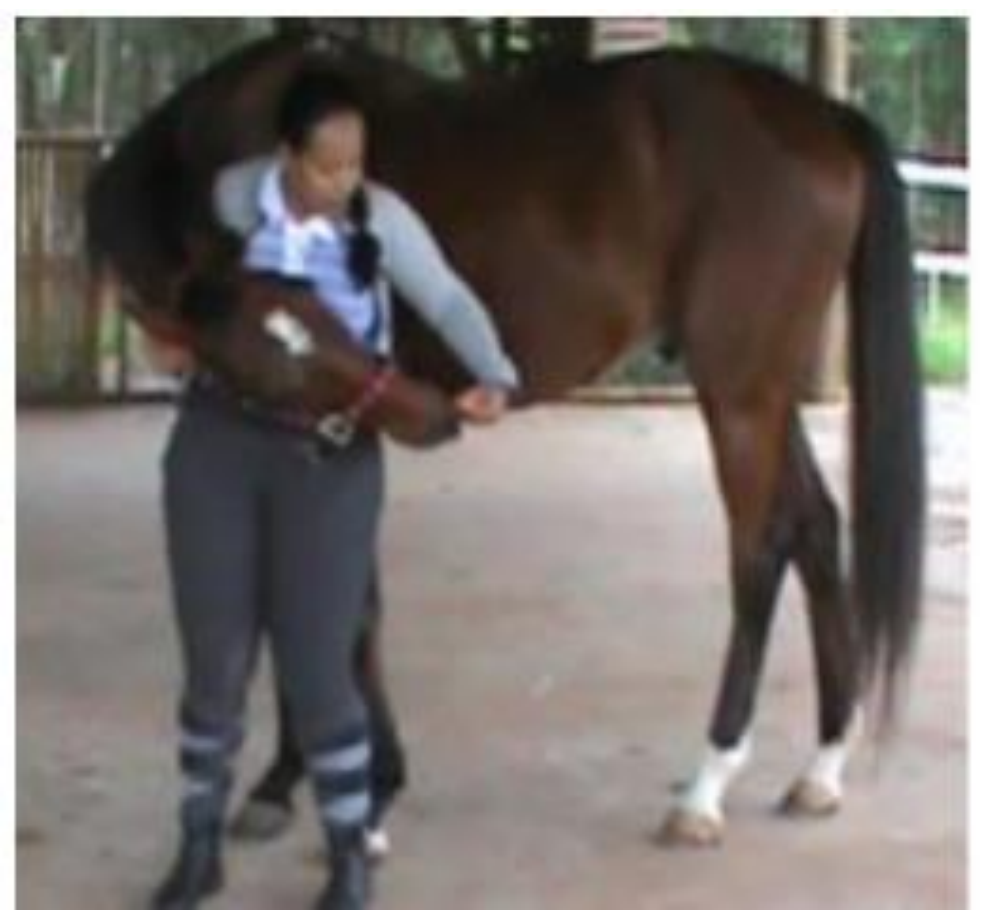

Figura 9. Flexão cervical lateral, com a cabeça na espádua.

Cada exercício de mobilização foi repetido por cinco vezes, para cada sessão de exercícios, mantidos por 5 segundos, e feito com auxílio de um petisco, para conduzir os cavalos às posições desejadas. O fortalecimento abdominal foi composto pelos exercícios de recuo (Figura 10), spinning (Figura 10) e flexão bilateral da pélvis (Figura 11) e, utilizando-se da passagem sobre obstáculo ao passo (Figura 10), para fortalecer os músculos estabilizadores da pélvis.

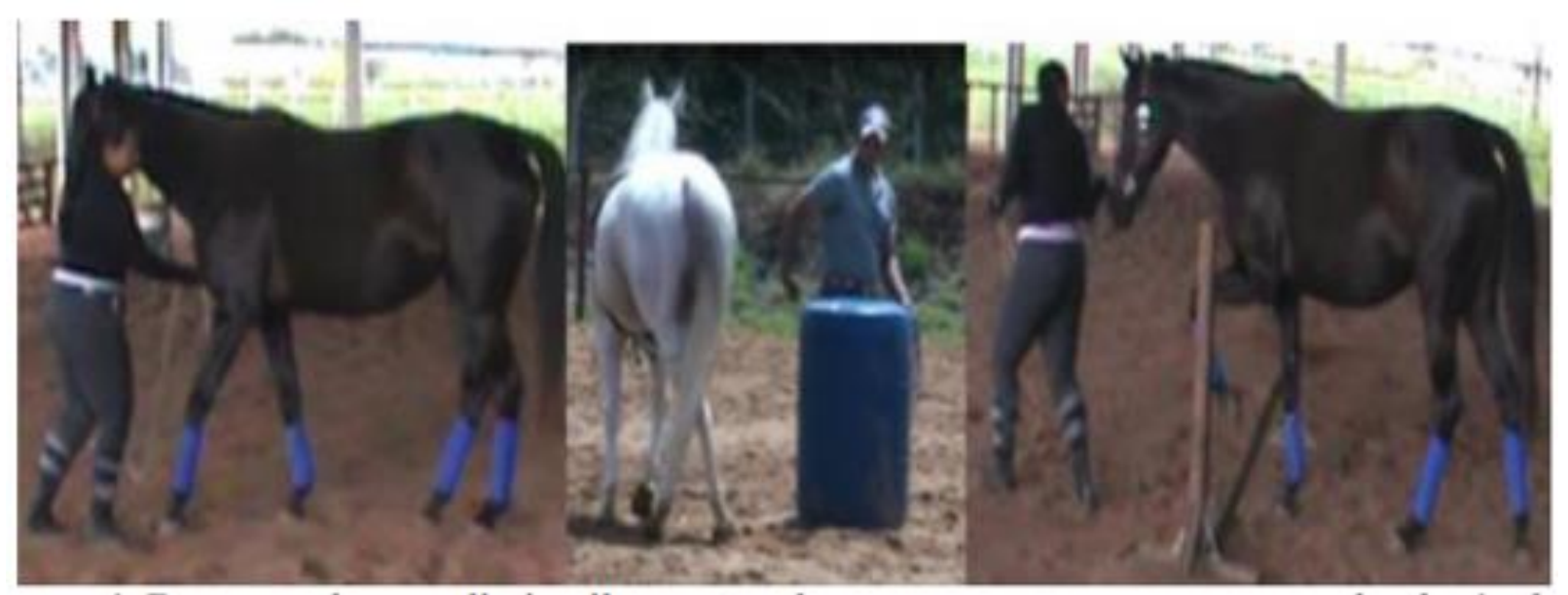

Figura 10. Da esquerda para direita, ilustrações do recuo, spnning e passagem pelo obstáculo 


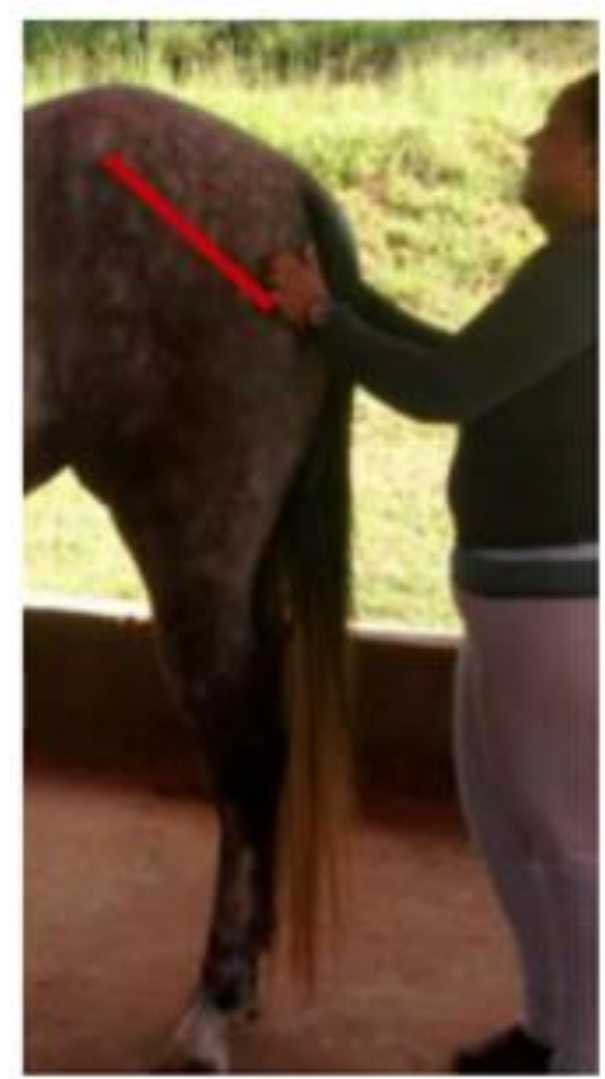

Figura 11. Flexão bilateral da pélvis.

Os exercícios de fortalecimento muscular seguiram a descrição detalhada contida no trabalho de HIGGINS (2009). Assim, o recuo foi feito em uma única série, de dez passos consecutivos em linha reta, o spinning foi realizado com auxílio de um tambor, perfazendo três repetições para cada lado por sessão, a inclinação da pélvis foi feita, gentilmente, por meio de ponto reflexo localizado entre o bíceps femoris e semitendinosus (cinco repetições por sessão) e a passagem ao passo pelo obstáculo, foi utilizado cavalete erguido a $40 \mathrm{~cm}$ de altura, durante dez minutos, nos sentidos horários e anti-horários. 


\section{RESULTADOS CIENTÍFICOS}

\subsection{Biomecânica do Andamento}

Na tabela 1 estão apresentados os valores médios das variáveis biomecânicas no andamento ao trote, de cavalos terapeutas submetidos a frequências semanais crescentes de execução da ginástica laboral. Após análise dos resultados foi verificada ausência de efeito significativo para o ganho na cadência ao trote $(\mathrm{P}>0,05)$. Contudo, foi observado melhora nos ganhos da regularidade e simetria $(\mathrm{P}<0,05)$, em que os melhores resultados foram encontrados aos cavalos submetidos a ginástica laboral realizada de três à quatro vezes/semana.

Tabela 1. Valores médios com desvio padrão $( \pm)$ dos ganhos das variáveis biomecânicas ao trote de cavalos terapeutas submetidos a frequências semanais crescentes de execução da ginástica laboral

\begin{tabular}{l|c|c|c|c|cc}
\hline \multirow{2}{*}{\multicolumn{1}{c|}{$\begin{array}{c}\text { Variável } \\
\text { Biomecânica }\end{array}$}} & \multicolumn{4}{c}{ Frequência semanal de execução da ginástica laboral } & Valor de \\
\cline { 2 - 6 } & $0 \mathrm{x} / \mathrm{sem}$. & $1 \mathrm{x} / \mathrm{sem}$. & $2 \mathrm{x} / \mathrm{sem}$. & $3 \mathrm{x} / \mathrm{sem}$. & $4 \mathrm{x} / \mathrm{sem}$. & $\mathrm{P}$ \\
\hline $\mathrm{G}-C A D^{1}$ & $-0,1 \pm 0,02$ & $-0,1 \pm 0,02$ & $-0,1 \pm 0,03$ & $0,1 \pm 0,01$ & $0,1 \pm 0,01$ & 0,0622 \\
(passada/seg) & & & & & & \\
G-REG $^{2}(/ 200)$ & $-51,9 \pm 2,61^{\mathrm{d}}$ & $-31,0 \pm 5,31^{\mathrm{c}}$ & $12,0 \pm 5,53^{\mathrm{b}}$ & $15,4 \pm 4,09^{\mathrm{a}}$ & $16,0 \pm 4,25^{\mathrm{a}}$ & 0,0001 \\
G-SIM $^{3}(\%)$ & $-45,7 \pm 5,75^{\mathrm{d}}$ & $-17,9 \pm 1,77^{\mathrm{c}}$ & $19,8 \pm 4,22^{\mathrm{a}}$ & $14,9 \pm 3,01^{\mathrm{ab}}$ & $20,6 \pm 5,66^{\mathrm{a}}$ & 0,0060 \\
\hline
\end{tabular}

${ }^{1} \mathrm{G}-\mathrm{CAD}=$ ganho na cadência; ${ }^{2} \mathrm{G}-\mathrm{REG}=$ ganho na regularidade; ${ }^{3} \mathrm{G}-\mathrm{SIM}=$ ganho na simetria. a,b,c,d Médias com letras diferentes na linha, diferem entre si pelo de Tukey.

O principal objetivo do treinamento, em relação ao andamento do trote de equinos, é promover a coordenação, equilíbrio e propulsão durante deslocamento (BIAU \& BARREY, 2004b). Assim, espera-se que um bom trote possua boa regularidade e simetria, realizados com elasticidade, mantendo-se a frequência de passada (BURLA et al., 2014). Os resultados mostrados na tabela 1 apresentam-se 
concordantes a estes propósitos, ou seja, manutenção da frequência da passada com incrementos na regularidade e simetria nos cavalos submetidos a ginástica laboral.

Oliveira et al. (2015), também observaram melhoras significativas na qualidade do movimento ao passo em cavalos de equoterapia submetidos a ginástica laboral realizada três vezes por semana. Ainda, o ganho na SIM, no atual trabalho, apresentouse como a variável biomecânica mais sensível a inclusão de rotina de exercícios laborais aos cavalos de terapia, apresentando incrementos positivos a partir da execução de duas sessões semanais. Isto pode ter ocorrido pela maior simetria muscular nos cavalos submetidos a ginástica laboral, resultando em ganhos na variável biomecânica SIM de 19,8 e 20,6 \%, para realização de duas e quatro sessões semanais, respectivamente.

Pesquisa realizada por Stubbs, et al. (2011), corroboram esta justificativa, em que a realização de exercícios de mobilização dinâmica em cavalos (cinco vezes/semana), promoveu aumentos na simetria da musculatura epaxial, mensurados por meio do ultrassom. Existe um consenso em que o peso e a força muscular sofrem interferência da idade do cavalo e, assim, podem influenciar a locomoção (BIAU \& BARREY, 2004a). Em se tratando de equinos idosos, como os utilizados na presente

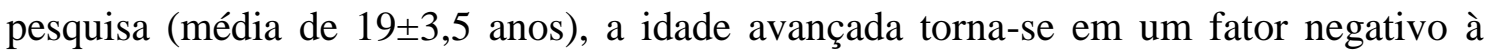
qualidade do movimento tridimensional.

Sendo assim, os bons resultados alcançados às variáveis biomecânicas (Tabela 1) foram oriundas da inclusão de exercícios físicos de suporte aos cavalos de equoterapia, como a ginástica laboral. Vale ressaltar que, as variáveis REG e SIM, além de qualificarem o movimento tridimensional do trote, são utilizadas como índices para identificar a ocorrência de claudicação nos cavalos em suas diversas modalidades esportivas (BARREY et al., 2002). 
Neste sentido, lopez-Sanromán et al. (2012), verificaram redução de 50\% no valor da REG em cavalos sedados com xilazina e monitorados biomecanicamente por meio do acelerômetro. O incremento no ganho destas variáveis observados na tabela 1 , em cavalos submetidos a ginástica laboral, a partir da frequência de duas sessões semanais, expressam o melhor deslocamento destes animais ao trote, de forma equilibrada e, consequentemente, sem claudicação. Esta resposta é de grande relevância, pois a claudicação estabelecida, mesmo quando não visível, interfere negativamente no bem-estar dos animais, ou seja, diminuindo a qualidade de vida dos equinos. Desta forma, a inclusão da ginástica laboral, por no mínimo duas vezes/semana, atua como ferramenta de prevenção à incidência de lesões que causam claudicação nos cavalos terapeutas.

Em relação ao comprimento da passada ao passo, este sofreu o efeito $(\mathrm{P}<0,05)$ do nível de atividade física realizado pelos cavalos terapeutas, no qual os cavalos submetidos a ginástica laboral superaram os valores encontrados aos grupos sedentários e à mobilização dinâmica (Tabela 2). Essa observação foi diferente do que Gomez Alvarez et al. (2006) descobriram durante um estudo sobre o efeito da posição cabeça/pescoço no treinamento de cavalos atletas sobre a cinemática linear do passo, no qual verificaram que este método de treino não interferiu no $\mathrm{CP}$. 
Tabela 2 - Valores médios da diferença entre as avaliações inicial e final do comprimento da passada (CP) e distância de passada (DP) ao passo, de cavalos terapeutas sedentários e submetidos a atividade física.

\begin{tabular}{|c|c|c|c|c|c|}
\hline \multirow{2}{*}{$\begin{array}{l}\text { Varáveis } \\
\text { (cm) }\end{array}$} & \multicolumn{3}{|c|}{ Tratamentos } & \multirow{2}{*}{ Valor de P } & \multirow{2}{*}{$\begin{array}{l}\text { Desvio } \\
\text { Padrão }\end{array}$} \\
\hline & $\mathrm{SD}^{1}$ & $\mathrm{MOB}^{2}$ & $\mathrm{GIN}^{3}$ & & \\
\hline $\mathrm{CP}$ ao passo & $0,67^{\mathrm{b}}$ & $2,33^{\mathrm{b}}$ & $10,67^{\mathrm{a}}$ & 0,0004 & 4,82 \\
\hline DP ao passo & $1,83^{\mathrm{b}}$ & $1,86^{\mathrm{b}}$ & $16,73^{\mathrm{a}}$ & 0,0002 & 7,65 \\
\hline
\end{tabular}

A questão racial do cavalo parece interferir mais efetivamente no $\mathrm{CP}$ a passo do que a atividade física. Neste sentido, Cano et al., (2001), analisaram a cinemática linear de cavalos das raças Andaluz, Árabe e Anglo-Árabe sobre o CP ao passo, verificando efeito significativo da raça para esta variável. Contudo, o atual ensaio utilizou cavalos sem raça definida, os quais apresentaram alterações significativas do $\mathrm{CP}$ ao passo quando submetidos à GIN, demonstrando a importância do exercício de suporte para a qualidade do passo em cavalos terapeutas.

A alteração da velocidade do passo pode ser importante para modificar o movimento do cavalo (DVORAKOVA et al., 2009). Janura et al. (2010) constataram um aumento do $\mathrm{CP}$ a passo $(\mathrm{P}<0,05)$ em cavalos de hipoterapia com o incremento da velocidade. Em pesquisa de Dvorakova et al. (2009), trabalhando também com cavalos de equoterapia submetidos a diferentes velocidades do passo, observou-se um valor para $\mathrm{CP}$ entre 128 e $132 \mathrm{~cm}$ para velocidades variando de 1,35 a $1,43 \mathrm{~m} / \mathrm{s}$. Similarmente ao observado na presente pesquisa, no qual o valor médio do $\mathrm{CP}$ ao passo foi de $136 \mathrm{~cm}$ (dado não apresentado), durante o período experimental para todos os tratamentos, mantendo-se velocidade constante do passo de $1,3 \mathrm{~m} / \mathrm{s}$ nas duas avaliações. Este $\mathrm{CP}$ ao passo de $136 \mathrm{~cm}$ para cavalos terapeutas apresentou-se abaixo ao $\mathrm{CP}$ de $175 \mathrm{~cm}$ 
verificado para cavalos atletas (BARREY et al., 2002), bem como foi inferior ao CP de $157 \mathrm{~cm}$ ao passo reunido (CLAYTON, 1995), demonstrando um encurtamento da passada ao passo nos cavalos de terapia.

O ajuste na distância de pegadas é o principal mecanismo para promover a mudança no comprimento da passada em todos os andamentos (CLAYTON, 2004). Essa observação foi também verificada na atual pesquisa, na qual a realização da ginástica laboral melhorou $(\mathrm{P}<0,05)$ a $\mathrm{DP}$ ao passo, promovendo um aumento da $\mathrm{DP}$ destes animais em comparação aos grupos sedentário e de mobilização dinâmica. Esta resposta demonstrou que os animais submetidos à GIN, possivelmente, engajaram mais os membros posteriores, sendo uma característica interessante à hipoterapia, pela possibilidade de se intensificar a oscilação do dorso de equinos por meio do componente vertical do movimento tridimensional. Tal suposição sobre o engajamento, ou seja, protração do membro posterior está fundamentada no trabalho de Hill e Crook (2010), no qual utilizaram o comprimento da passada para expressar esta característica.

Na tabela 3 encontram-se os valores médios da DP obtidas nas avaliações inicial e final dos cavalos terapeutas sedentários e submetidos à MOB e à GIN. Observou-se efeito significativo, no decorrer do ensaio, nos equinos exercitados com a GIN, corroborando os dados contidos na tabela 1. Assim, os cavalos exercitados por meio da GIN apresentaram maior engajamento do membro posterior, denotado pela melhor protração do mesmo, o que reflete uma maior flexão da pélvis (HODSON, 2001). Portanto, acredita-se que esta resposta dos cavalos submetidos à GIN tenha sido uma consequência do exercício de inclinação da pélvis contido no programa físico da ginástica laboral. De acordo com Stubbs e Clayton (2008) e Higgins (2009a), este exercício provoca a flexão da articulação lombossacral, permitindo uma maior inclinação da pélvis e, assim, auxiliando no engajamento. 
Tabela 3 - Valores médios das avaliações inical e final do comprimento da passada ao passo de cavalos terapeutas sedentários e submetidos a atividade física.

\begin{tabular}{lcccc}
\hline \multirow{2}{*}{ Tratamentos } & \multicolumn{2}{c}{ Comprimento da passada $(\mathrm{cm})$} & \multirow{2}{*}{$\begin{array}{c}\text { Valor de } \\
\text { P }^{*}\end{array}$} & Desvio \\
\cline { 2 - 3 } & Inicial $^{1}$ & Final $^{1}$ & & Padrão \\
\hline Sedentário & $-15,00$ & $-13,17$ & 0,6318 & 4,01 \\
Mobilização Dinâmica & $-8,30$ & $-6,44$ & 0,2910 & 1,96 \\
Ginástica Laboral & $-11,43$ & 5,30 & 0,0010 & 3,07 \\
\hline *Test T pareado. & & & &
\end{tabular}

$\mathrm{Na}$ análise da tabela 2, nota-se que a DP ao passo permaneceu inalterada $(\mathrm{P}>0,05)$ entre a aferição inicial e final do experimento para os cavalos terapeutas dos grupos SED (média de - 14,09 cm) e MOB (média de - 7,37 cm), demonstrando que os membros pélvicos dos animais projetaram-se no chão 14 e $7 \mathrm{~cm}$ atrás do membro torácico. Os cavalos submetidos à GIN iniciaram a pesquisa com um antepistamento de - $11 \mathrm{~cm}$ e, após três meses de GIN, progrediram para uma DP positiva de $5 \mathrm{~cm}$ $(\mathrm{P}<0,05)$, ou seja, transpistando discretamente o membro torácico. Waldern et al. (2009), explicaram a ocorrência da DP negativa nos cavalos em treinamento por meio do mecanismo de arco e corda. Este mecanismo considera que, para o cavalo conseguir flexionar o dorso e permitir a colocação do membro pélvico bem abaixo do corpo (sobrepistar ou transpistar), o dorso deve estar descontraído. Assim, pode-se inferir que os cavalos terapeutas do presente ensaio que não estavam realizando atividade física apresentaram um dorso em extensão e endurecido como consequência do sedentarismo, o que pode colaborar para o desenvolvimento da lombalgia. 


\subsection{Movimento tridimensional}

Pesquisa utilizando cavalos de equoterapia foi conduzida para analisar a cinética e cinemática do movimento tridimensional nos andamentos ao passo e trote destes animais submetidos a ginástica laboral, em comparação ao grupo controle. Os tratamentos consistiram em um total de cinco grupos experimentais, compostos por grupo controle (sem realização de exercícios) e de quatro grupos testes de cavalos submetidos a ginástica laboral, com frequências crescentes semanais de realização (1 à 4x/semana). Foram mensuradas, por meio do acelerômetro Equimetrix, as variáveis referentes à cinética, forças dorso-ventral (FDV), médio-lateral (FML) e anteroposterior (FAP), bem como as variáveis cinemáticas, como, os deslocamentos dorsoventral (DDV), médio-lateral (DML) e antero-posterior (DAP) para avaliar a qualidade do movimento tridimensional nos andamentos passo e trote.

Na tabela 4 encontram-se os resultados desta pesquisa, em relação os valores médios observados às variáveis cinéticas, no andamento ao passo, de cavalos terapeutas submetidos ou não a ginástica laboral. Na avaliação inicial dos cavalos, no andamento ao passo, não se verificou efeito significativo entre os grupos experimentais às variáveis cinéticas estudadas. 
Tabela 4 - Valores médios ( \pm desvio padrão) de variáveis cinéticas no andamento ao passo, de cavalos terapeutas submetidos ou não a ginástica laboral, nas avaliações inicial e final.

\begin{tabular}{|c|c|c|c|c|c|c|}
\hline \multirow{2}{*}{$\begin{array}{l}\text { Variável } \\
\text { (W/kg) }\end{array}$} & \multicolumn{5}{|c|}{ Tratamentos - Frequência semanal de realização da ginástica laboral } & \multirow{2}{*}{ Valor de $\mathrm{P}$} \\
\hline & 0 & 1 & 2 & 3 & 4 & \\
\hline \multicolumn{7}{|c|}{ Avaliação Inicial } \\
\hline $\mathrm{FDV}^{1}$ & $0,65 \pm 0,42$ & $1,02 \pm 0,56$ & $0,46 \pm 0,25$ & $0,39 \pm 0,21$ & $0,80 \pm 0,43$ & 0,1587 \\
\hline FAP $^{2}$ & $1,95 \pm 0,46$ & $3,10 \pm 1,58$ & $1,73 \pm 1,47$ & $1,69 \pm 0,50$ & $2,86 \pm 1,31$ & 0,1324 \\
\hline $\mathrm{FML}^{3}$ & $1,90 \pm 0,94$ & $1,98 \pm 1,07$ & $1,43 \pm 0,68$ & $0,98 \pm 0,51$ & $1,63 \pm 0,65$ & 0,0606 \\
\hline \multicolumn{7}{|c|}{ Avaliação Final } \\
\hline FDV & $0,56 \pm 0,20^{\mathrm{a}}$ & $0,93 \pm 0,15^{\mathrm{b}}$ & $0,53 \pm 0,17^{\mathrm{a}}$ & $0,53 \pm 0,07^{\mathrm{a}}$ & $1,12 \pm 0,15^{\mathrm{b}}$ & 0,0036 \\
\hline FAP & $2,00 \pm 1,25^{\mathrm{a}}$ & $2,93 \pm 0,52^{a b}$ & $2,12 \pm 0,91^{\mathrm{a}}$ & $1,91 \pm 0,69^{\mathrm{a}}$ & $3,58 \pm 0,68^{\mathrm{b}}$ & 0,0007 \\
\hline FML & $1,59 \pm 0,29^{a}$ & $2,42 \pm 0,16^{\mathrm{b}}$ & $1,58 \pm 0,27^{\mathrm{a}}$ & $1,69 \pm 0,26^{\mathrm{ab}}$ & $2,41 \pm 0,36^{\mathrm{b}}$ & 0,0119 \\
\hline
\end{tabular}

Os valores médios apresentados aos tratamentos foram de 0,66, 2,27 e 1,58 $\mathrm{W} / \mathrm{kg}$ para as forças dorso-ventral, antero-posterior e médio-lateral, respectivamente, no andamento ao passo, para cavalos terapeutas na avaliação inicial, ou seja, sem a interferência da ginástica laboral. O valor médio para a FAP de 2,27 W/kg, da presente pesquisa, foi superior ao encontrado por López-Sanromán et al. (2012), trabalhando com cavalos, possuindo idade média de 15 anos, de 1,07 W/kg, e inferior ao observado em cavalos da raça Mangalarga Marchador de 6,30 W/kg (SOARES, 2017). Ainda, resultados superiores foram observados por Barrey et al. (2002), utilizando cavalos de adestramento, em que o valor da força dorso-ventral verificada foi de 1,13 W/kg. Estas divergências nos resultados obtidos entre as pesquisas devem-se a raça de cavalo utilizado, bem como ao nível de equitação dos mesmos. Assim, os valores inferiores 
observados na atual pesquisa eram esperados, pois os cavalos usados possuem nível básico de equitação, além de idade avançada e sem a realização de atividade física de suporte, enquanto que os animais da pesquisa supracitada pertencem ao grupo de adestramento de alto rendimento esportivo.

$\mathrm{Na}$ avaliação final, se verificou diferenças significativas entre os grupos experimentais, às variáveis cinéticas no andamento ao passo, no qual os maiores valores observados foram encontrados ao grupo de cavalos submetidos a ginástica laboral na frequência de 4x/semana (Tabela 4). Os valores de 1,12, 3,58 e 2,41 W/kg da atual pesquisa para FDV, FAP, FML, respectivamente, em cavalos terapeutas submetidos a ginástica laboral 4x/semana, se igualam ao valor obtido por Barrey et al., (2002) de 1,13 W/kg para FDV em cavalos de adestramento de alto rendimento. Este resultado, aos cavalos terapeutas, foi muito expressivo e importante para as forças envolvidas com o movimento tridimensional, ou seja, tornando estes animais mais eficientes na produção de força nos três vetores que compõem o movimento tridimensional.

Na tabela 5 encontram-se os valores médios observados às variáveis cinéticas, no andamento ao trote, de cavalos terapeutas submetidos ou não a ginástica laboral. Na avaliação inicial dos cavalos, no andamento ao trote, não se verificou efeito significativo entre os grupos experimentais às variáveis cinéticas estudadas. 
Tabela 5 - Valores médios \pm desvio padrão de variáveis cinéticas no andamento ao trote, de cavalos terapeutas submetidos ou não a ginástica laboral, nas avaliações inicial e final.

\begin{tabular}{|c|c|c|c|c|c|c|}
\hline \multirow[b]{2}{*}{$\begin{array}{c}\text { Variável } \\
(\mathrm{W} / \mathrm{kg})\end{array}$} & \multicolumn{5}{|c|}{ Tratamentos - Frequência semanal de realização da ginástica laboral } & \multirow{2}{*}{ Valor de $\mathrm{P}$} \\
\hline & 0 & 1 & 2 & 3 & 4 & \\
\hline \multicolumn{7}{|c|}{ Avaliação Inicial } \\
\hline $\mathrm{FDV}^{1}$ & $13,85 \pm 4,56$ & $10,20 \pm 4,94$ & $13,77 \pm 5,14$ & $10,46 \pm 4,92$ & $12,38 \pm 4,10$ & 0,1460 \\
\hline FAP $^{2}$ & $8,21 \pm 4,00$ & $7,18 \pm 1,72$ & $14,53 \pm 10,08$ & $11,06 \pm 3,51$ & $8,03 \pm 0,71$ & 0,0575 \\
\hline $\mathrm{FML}^{3}$ & $2,80 \pm 1,74$ & $2,45 \pm 1,81$ & $5,41 \pm 2,36$ & $5,35 \pm 4,35$ & $2,92 \pm 2,82$ & 0,5481 \\
\hline \multicolumn{7}{|c|}{ Avaliação Final } \\
\hline FDV & $12,33 \pm 2,19^{\mathrm{a}}$ & $12,0 \pm 2,01^{\mathrm{a}}$ & $13,05 \pm 0,90^{\mathrm{b}}$ & $17,84 \pm 1,04^{\mathrm{c}}$ & $13,63 \pm 2,15^{\mathrm{bc}}$ & 0,0065 \\
\hline FAP & $8,5 \pm 4,15^{\mathrm{a}}$ & $11,93 \pm 2,02^{\mathrm{b}}$ & $20,42 \pm 14,61^{\mathrm{c}}$ & $17,40 \pm 9,32^{\mathrm{c}}$ & $11,86 \pm 1,93^{b}$ & 0,0494 \\
\hline FML & $2,63 \pm 0,80^{\mathrm{a}}$ & $3,37 \pm 0,99^{\mathrm{ab}}$ & $5,00 \pm 1,25^{\mathrm{b}}$ & $7,35 \pm 3,45^{\mathrm{c}}$ & $6,67 \pm 0,84^{\mathrm{c}}$ & 0,0001 \\
\hline
\end{tabular}

Os valores médios apresentados aos tratamentos foram de 12,13, 9,80 e 3,79 $\mathrm{W} / \mathrm{kg}$ para as forças dorso-ventral, antero-posterior e médio-lateral, respectivamente, no andamento ao trote, para cavalos terapeutas na avaliação inicial. A força dorso-ventral na avaliação inicial de cavalos terapeutas encontrou-se abaixo ao observado por Biau et al. (2002), de 15,6 W/kg no andamento ao trote. Novamente, estas divergências nos resultados obtidos entre as pesquisas devem-se principalmente ao nível de equitação dos cavalos. Assim, os valores inferiores observados na atual pesquisa eram esperados, pois os animais usados possuem nível básico de equitação, além de idade avançada e sem a realização de atividade física de suporte, enquanto que os cavalos da pesquisa supracitada pertencem ao grupo de adestramento e salto de alto rendimento esportivo. Ainda, a escassez de pesquisas publicadas na área da cinética do movimento de equinos 
e as diferentes metodologias utilizadas às suas mensurações limitam o aprofundamento da discussão dos resultados observados.

$\mathrm{Na}$ avaliação final, se verificou diferenças significativas entre os grupos experimentais, às variáveis cinéticas no andamento ao trote, no qual os maiores valores observados foram encontrados aos grupos de cavalos submetidos a ginástica laboral na frequência semanal a partir de três sessões (Tabela 5). O valor médio da FDV de 15,74 $\mathrm{W} / \mathrm{kg}$, aos cavalos terapeutas submetidos a ginástica laboral por 3 e 4x/semana, superaram os valores encontrados por Biau et al. (2202) e Biau \& Barrey (2004a) de 15,6 e 10,4 W/kg, respectivamente. Contudo, esta variável foi inferior ao valor obtido por Barrey et al. (2002), de 22,01 W/kg, para cavalos de adestramento de alto rendimento e da raça sela francesa.

Dentre as variáveis cinéticas envolvidas com o movimento tridimensional, a FDV é uma das mais utilizadas nas pesquisas científicas. A mesma expressa a quantidade de força envolvida no deslocamento do corpo do cavalo no sentido dorsoventral, ou seja, no instante entre os momentos de suspensão e de impacto ao solo dos membros (BIAU et al., 2002). Sendo assim, Biau \& Barrey (2004b) avaliaram a importância das variáveis cinéticas na movimentação de potros para modalidade de adestramento, objetivando índices para seleção precoce destes animais, e encontraram que FDV, é a principal característica com influência sobre qualidade do passo e trote. Portanto, pode-se inferir que os cavalos terapeutas quando submetidos a ginástica laboral tem como consequência, a melhora significativa na qualidade cinética do movimento ao passo e no trote, que poderá corroborar na eficiência de recuperação dos praticantes nas sessões de equoterapia. 
$\mathrm{Na}$ tabela 6 encontram-se os valores médios observados às variáveis cinemáticas, no andamento ao passo, de cavalos terapeutas submetidos ou não a ginástica laboral. Na avaliação inicial dos cavalos, no andamento ao passo, não se verificou efeito significativo entre os grupos experimentais às variáveis cinemáticas estudadas.

Tabela 6 - Valores médios \pm desvio padrão de variáveis cinemáticas no andamento ao passo, de cavalos terapeutas submetidos ou não a ginástica laboral, nas avaliações inicial e final.

\begin{tabular}{|c|c|c|c|c|c|c|}
\hline \multirow[b]{2}{*}{$\begin{array}{c}\text { Variável } \\
\text { (cm) }\end{array}$} & \multicolumn{5}{|c|}{ Tratamentos - Frequência semanal de realização da ginástica laboral } & \multirow[b]{2}{*}{ Valor de $\mathrm{P}$} \\
\hline & 0 & 1 & 2 & 3 & 4 & \\
\hline \multicolumn{7}{|c|}{ Avaliação Inicial } \\
\hline $\mathrm{DDV}^{1}$ & $2,54 \pm 1,78$ & $3,50 \pm 1,95$ & $1,70 \pm 0,98$ & $2,50 \pm 0,99$ & $3,17 \pm 1,20$ & 0,1526 \\
\hline $\mathrm{DAP}^{2}$ & $7,76 \pm 2,44$ & $13,82 \pm 11,46$ & $9,32 \pm 7,98$ & $12,9 \pm 646$ & $12,63 \pm 5,6$ & 0,4067 \\
\hline $\mathrm{DML}^{3}$ & $7,48 \pm 1,83$ & $6,62 \pm 1,80$ & $5,40 \pm 3,02$ & $7,00 \pm 3,26$ & $7,89 \pm 4,24$ & 0,4750 \\
\hline \multicolumn{7}{|c|}{ Avaliação Final } \\
\hline DDV & $2,00 \pm 0,63^{\mathrm{a}}$ & $3,33 \pm 1,21^{\mathrm{b}}$ & $2,80 \pm 0,83^{\mathrm{ab}}$ & $3,13 \pm 0,99^{b}$ & $3,50 \pm 1,20^{b}$ & 0,0163 \\
\hline DAP & $7,59 \pm 3,35^{\mathrm{a}}$ & $10,9 \pm 1,12^{\mathrm{ab}}$ & $9,70 \pm 3,31^{\mathrm{ab}}$ & $13,34 \pm 8,48^{\mathrm{b}}$ & $12,58 \pm 3,05^{\mathrm{b}}$ & 0,0050 \\
\hline DML & $8,08 \pm 2,48$ & $7,55 \pm 4,12$ & $8,62 \pm 4,96$ & $10,23 \pm 3,73$ & $8,21 \pm 2,54$ & 0,5860 \\
\hline
\end{tabular}

Os valores médios apresentados aos tratamentos foram de 2,68, 11,29 e 6,88 cm para os deslocamentos dorso-ventral, antero-posterior e médio-lateral, respectivamente, no andamento ao passo, para cavalos terapeutas na avaliação inicial. O valor médio para o DDV de 2,68 cm, da presente pesquisa, foi inferior às pesquisas de Biau et al. (2002) e Soares (2017), utilizando cavalos de equitação de alto rendimento e da raça Mangalarga Marchador, respectivamente, com valor de 4,00 $\mathrm{cm}$, no andamento ao 
passo. Desta forma, os cavalos terapeutas do atual trabalho, apresentavam-se endurecidos, na primeira avaliação experimental, devido a pouca quantidade de movimento dorso-ventral. Isto causa efeito prejudicial direto à qualidade do movimento tridimensional nestes cavalos, que pode interferir negativamente na reabilitação do praticante de equoterapia.

$\mathrm{Na}$ avaliação final, se verificou diferenças significativas entre os grupos experimentais, às variáveis cinemáticas, DDV e DAP no andamento ao passo, no qual os maiores valores observados foram encontrados ao grupo de cavalos submetidos a ginástica laboral na frequência de 4x/semana (Tabela 6). Ainda, o valor médio para o DDV, da atual pesquisa, ao grupo de cavalos terapeutas submetidos à ginástica laboral na frequência de 4x/semana, apresentou-se semelhante às pesquisas de Biau et al. (2002) e Soares (2017). Tais resultados demonstram que a realização da ginástica laboral em cavalos terapeutas melhora cinematicamente duas variáveis que compõem o movimento tridimensional (deslocamentos dorso-ventral e antero-posterioi), interferindo assim, beneficamente na qualidade do andamento ao passo destes animais.

$\mathrm{Na}$ tabela 7 encontram-se os valores médios observados às variáveis cinemáticas, no andamento ao trote, de cavalos terapeutas submetidos ou não a ginástica laboral. Na avaliação inicial dos cavalos, no andamento ao trote, não se verificou efeito significativo entre os grupos experimentais às variáveis cinemáticas estudadas. 
Tabela 7 - Valores médios \pm desvio padrão de variáveis cinemáticas no andamento ao trote, de cavalos terapeutas submetidos ou não a ginástica laboral, nas avaliações inicial e final.

\begin{tabular}{|c|c|c|c|c|c|c|}
\hline \multirow{2}{*}{$\begin{array}{c}\text { Variável } \\
(\mathrm{cm})\end{array}$} & \multicolumn{5}{|c|}{$\begin{array}{c}\text { Tratamentos - Frequência semanal de realização da ginástica } \\
\text { laboral }\end{array}$} & \multirow{2}{*}{ Valor de $\mathrm{P}$} \\
\hline & 0 & 1 & 2 & 3 & 4 & \\
\hline \multicolumn{7}{|c|}{ Avaliação Inicial } \\
\hline $\mathrm{DDV}^{1}$ & $9,85 \pm 1,95$ & $9,33 \pm 2,16$ & $9,29 \pm 2,06$ & $11,63 \pm 2,33$ & $10,87 \pm 0,83$ & 0,0942 \\
\hline $\mathrm{DAP}^{2}$ & $5,98 \pm 2,28$ & $6,70 \pm 2,29$ & $9,00 \pm 3,93$ & $7,70 \pm 1,88$ & $6,99 \pm 1,23$ & 0,1235 \\
\hline $\mathrm{DML}^{3}$ & $1,94 \pm 0,74$ & $2,17 \pm 0,95$ & $3,70 \pm 1,07$ & $3,56 \pm 0,94$ & $2,34 \pm 0,83$ & 0,0579 \\
\hline \multicolumn{7}{|c|}{ Avaliação Final } \\
\hline DDV & $9,46 \pm 0,88^{\mathrm{a}}$ & $9,50 \pm 1,07^{\mathrm{a}}$ & $9,67 \pm 1,03^{\mathrm{ab}}$ & $11,50 \pm 2,98^{\mathbf{b}}$ & $11,38 \pm 1,60^{\mathrm{b}}$ & 0,0352 \\
\hline DAP & $6,88 \pm 1,96^{\mathrm{a}}$ & $9,33 \pm 0,99^{c}$ & $15,34 \pm 1,67^{\mathrm{d}}$ & $8,84 \pm 2,96^{\mathrm{b}}$ & $9,50 \pm 2,26^{\mathrm{c}}$ & 0,0012 \\
\hline DML & $2,00 \pm 0,20^{\mathrm{a}}$ & $2,63 \pm 0,58^{\mathrm{a}}$ & $3,78 \pm 0,91^{\mathrm{b}}$ & $4,58 \pm 1,07^{\mathrm{c}}$ & $4,63 \pm 1,55^{\mathrm{c}}$ & 0,0001 \\
\hline
\end{tabular}

Os valores médios apresentados aos tratamentos foram de 10,19, 7,27 e 2,74 cm para os deslocamentos dorso-ventral, antero-posterior e médio-lateral, respectivamente, no andamento ao trote, para cavalos terapeutas na avaliação inicial. O valor médio para o DDV de 10,19 cm, da presente pesquisa, foi inferior às pesquisas de Biau et al. (2002) e Biau \& Barrey (2004), utilizando cavalos de equitação de alto rendimento, com valores de 11 e $13 \mathrm{~cm}$ no andamento ao trote, respectivamente. Isto denota mais uma vez a falta de qualidade no movimento tridimensional de cavalos terapeutas quando não realizam atividade física complementar como a ginástica laboral.

$\mathrm{Na}$ avaliação final, se verificou diferenças significativas entre os grupos experimentais, às variáveis cinemáticas estudadas ao trote, no qual os maiores valores observados foram encontrados ao grupo de cavalos submetidos a ginástica laboral na 
frequência de 4x/semana (Tabela 7). Verificou-se similaridade entre os valores do DDV, no andamento ao trote, dos cavalos terapeutas realizando ginástica laboral $4 \mathrm{x} /$ semana com àqueles encontrados na literatura, citados anteriormente (BIAU et al., 2002 e BARREY et al., 2002). Os deslocamentos observados nos três vetores, no andamento ao trote (Tabela 7), foram significativamente maiores ao grupo de cavalos terapeutas submetidos a ginástica laboral por 4x/semana, contribuindo no ganho de qualidade do movimento tridimensional neste andamento. Ainda, como esperado, os cavalos submetidos a ginástica laboral que obtiveram ganhos cinéticos $(\mathrm{P}<0,05)$ produziram aumentos significativos nos deslocamentos cinemáticos lineares, tornandose em cavalos com melhor qualidade na biomecânica do movimento tridimensional, prérequisito para o bom uso do cavalo como ferramenta reabilitadora aos praticantes de equoterapia.

Deve-se ressaltar que, cavalos se deslocando ao passo de forma encurtada e com alta frequência de passada, denotam animais com fraqueza na cinética de propulsão, bem como menores amplitudes no movimento tridimensional, ou seja, oferecendo menos estímulos aos praticantes durante a sessão. Ainda, tem que se atentar ao fato que nestas condições de movimentação disfuncional, o cavalo terapeuta pode estar desfrutando de desconforto musculoesquelético, algo que realmente tem que ser minimizado nos centros de equoterapia.

\subsection{Musculatura Epaxial}

Os músculos podem ser classificados quanto à função como excêntrico, isométrico ou concêntrico, dependendo se os períodos de atividade muscular ocorrem durante o alongamento, manutenção do comprimento ou encurtamento da fascícula muscular, respectivamente. As contrações excêntricas absorvem trabalho mecânico 
enquanto que as concêntricas geram trabalho mecânico (WAKELING et al., 2007). Assim, estas contrações atuam em sincronismo durante a movimentação do cavalo a passo, ou seja, há contração excêntrica da musculatura dorsal no momento em que a cadeia flexora, representada pelos músculos abdominais, se encontra em contração concêntrica (HIGGINS, 2009b).

Portanto, a ação dos músculos abdominais torna-se um fator importante na qualidade do passo dos equinos, provocando a flexão do dorso e, assim, contribuindo possivelmente no engajamento dos membros posteriores. Zsoldos et al. (2010) relataram a ocorrência de uma correlação positiva e significativa entre a atividade dos músculos abdominais, reto e oblíquo, e a protração dos membros pélvicos. Os resultados da atual pesquisa fornecem uma evidência indireta de um mecanismo similar provocada pelos músculos abdominais, pois somente os cavalos terapeutas submetidos a exercícios de fortalecimento abdominal inseridos na GIN apresentaram uma DP significativamente melhor (Tabela 3), ou seja, com maior protração do membro posterior.

O Longíssimus dorsi (LD) é o maior músculo epaxial, e se localiza entre as regiões torácica e lombar dos equinos (WAKELING et al., 2007). Na atual pesquisa, a hipertrofia do LD $(\mathrm{P}>0,05)$ não foi observada, apesar de que todos os grupos experimentais apresentaram um incremento numérico nesta medida (Tabela 3), denotando talvez que o tempo de três meses de atividade física não tenha sido suficiente para provocar as transformações de maneira significativa. Similarmente, O'Connor et al. (2002) não observaram hipertrofia do LD em cavalos treinados com sobrecarga de 45 kg de peso aplicada sobre o dorso, em comparação ao treino convencional. Ainda, Cottriall et al. (2009) também não verificaram uma atividade muscular aumentada do LD por meio de eletromiografia em cavalos treinados com a rédea Pessoa. Isto implica 
que o LD foi pouco exigido durante os exercícios avaliados nos cavalos terapeutas (Tabela 8).

Tabela 8 - Valores médios da diferença entre as avaliações inicial e final do comprimento da passada (CP) e distância de passada (DP) ao passo, de cavalos terapeutas sedentários e submetidos a atividade física.

\begin{tabular}{|c|c|c|c|c|c|}
\hline \multirow{2}{*}{ Varável } & \multicolumn{3}{|c|}{ Tratamento } & \multirow{2}{*}{ Valor de $\mathrm{P}$} & \multirow{2}{*}{$\begin{array}{l}\text { Desvio } \\
\text { Padrão }\end{array}$} \\
\hline & $\mathrm{SD}^{1}$ & $\mathrm{MOB}^{2}$ & $\mathrm{GIN}^{3}$ & & \\
\hline Longissimus dorsi (cm) & 2,38 & 3,98 & 2,43 & 0,0685 & 2,91 \\
\hline Musculus multifidus $\left(\mathrm{cm}^{2}\right)$ & $-0,55^{\mathrm{b}}$ & $3,55^{\mathrm{a}}$ & $3,78^{\mathrm{a}}$ & 0,0040 & 6,48 \\
\hline
\end{tabular}

De acordo com Groesel et al. (2010), a principal atividade do LD está na ação estabilizadora da coluna vertebral por meio da extensão do dorso (McGOWAN et al., 2007), além de contribuir para o endurecimento da coluna durante o deslocamento do animal com a finalidade de limitar excessivos movimentos rotacionais, dorso/ventral e lateral (WAKELING, et al., 2007). Entretanto, quando encurtado ou com excessivo endurecimento, o LD pode atuar desfavoravelmente na qualidade do passo por interferir de forma negativa na flexão do dorso do cavalo, como no caso dos cavalos terapeutas sedentários (Tabela 8).

Assim, exercícios de alongamento da região toracolombar são fundamentais ao funcionamento correto desta musculatura e, consequentemente, à boa ação biomecânica, além de trazer alívio à tensão muscular (HIGGINS, 2009b). Na presente pesquisa, os exercícios de alongamento estiveram presentes no grupo experimental de GIN. Apesar da hipertrofia do LD não ter sido identificada nos cavalos exercitados com a GIN, os 
exercícios de alongamento contidos neste programa possivelmente contribuíram na melhora da DP deste grupo (Tabela 8).

Este trabalho avaliou e identificou de maneira inédita a hipertrofia do musculus multifidus em cavalos terapeutas como resposta aos exercícios de MOB e GIN. O estudo comprovou que os exercícios de mobilização dinâmica ou associada ao fortalecimento muscular (GIN) em cavalos de equoterapia possuem a capacidade de muscular o dorso do cavalo, conforme aumento significativo $(\mathrm{P}<0,05)$ na área transversal do MM (Tabela 8). Similarmente, Stubbs et al. (2011) verificaram uma hipertrofia na área transversal do MM na L5 em cavalos da raça árabe submetidos a exercícios terapêuticos por meio de mobilização dinâmica, realizados cinco vezes por semana durante três meses, nos quais observou-se um valor médio final de $11 \mathrm{~cm}^{2}$. Tal resultado foi similar ao encontrado na avaliação final da atual pesquisa, na qual se observou um valor médio de 10,62 $\mathrm{cm}^{2}$ nos grupos MOB e GIN (Tabela 9). Contudo, ambas as atividades, mobilização dinâmica e ginástica laboral, resultaram em equinos com hipertrofia significativa do MM.

Tabela 9 - Valores médios das avaliações inical e final do musculus multifidus de cavalos terapeutas sedentários e submetidos a atividade física.

\begin{tabular}{lcccc}
\hline \multirow{2}{*}{ Tratamentos } & \multicolumn{2}{c}{ Musculus multifidus $\left(\mathrm{cm}^{2}\right)$} & \multirow{2}{*}{ Valor de P* } & \multirow{2}{*}{ Desvio } \\
\cline { 2 - 3 } & Inicial $^{1}$ & Final $^{1}$ & & Padrão \\
\hline Sedentário & 7,57 & 7,02 & 0,9083 & 2,17 \\
Mobilização Dinâmica & 6,83 & 10,38 & 0,0215 & 3,15 \\
Ginástica Laboral & 7,08 & 10,86 & 0,0407 & 4,37 \\
\hline * Test t pareado. & & &
\end{tabular}

O musculus multifidus é um músculo profundo que se situa medialmente ao LD, não sendo acessível por meio de avaliação visual. Sua origem ocorre a partir dos 
processos transversos das vértebras torácicas, lombares e sacrais (STUBBS et al., 2006). Funcionalmente, este músculo é importante na proteção contra a produção de rotação anormal e na distribuição de força pela coluna vertebral, gerada pelos músculos pélvicos (McGOWAN et al., 2007). Pesquisadores têm sugerido que o MM produz estabilização segmental e controle da coluna vertebral em cavalos, permitindo uma movimentação intervertebral próxima da posição neutra durante o deslocamento do animal (HAUSSLEr et al., 2007; STUBBS et al., 2006). Devido à importância do MM sobre a estabilização da coluna vertebral dos equinos, a utilização de exercícios que promova sua hipertrofia de maneira rápida torna-se primordial na equoterapia, pois os praticantes provocam intensos desequilíbrios de peso sobre o dorso do cavalo (ROSA, 2006).

Deve-se salientar que os trabalhos científicos com cavalos de equoterapia não têm apresentado como objetivo os efeitos da atividade física, bem como dados sobre a variável DP são inexistentes. A partir dos resultados obtidos no atual ensaio percebe-se que a DP pode ser melhorada por meio de atividade física, atuando diretamente sobre o CP. Tal observação indica a eficácia do treinamento em melhorar a qualidade do passo de cavalos terapeutas. Os trabalhos consultados apontam que a cinemática da coluna vertebral dos equinos é afetada pela DP, com a possibilidade de se melhorar o movimento tridimensional do dorso dos cavalos. Ainda, a participação muscular nestes eventos é de suma importância, pois os membros são movidos pela ação da muscultura em um trabalho conjunto entre as cadeias flexora e extensora. Portanto, torna-se necessária a inclusão destes parâmetros nas pesquisas que objetivam avaliar cavalos de hipoterapia, assim como atentar para a necessidade de exercícios de rotina para estes animais, a fim de que seja possível sua atuação como ferramentas eficientes nos programas de equoterapia aos praticantes, preservando-se o bem-estar dos mesmos. 


\subsection{Capacidade de Suporte do Dorso}

Em estudo recente conduzido em centro de equoterapia, foram utilizados 18 cavalos mestiços, para avaliar se o movimento tridimensional do cavalo terapeuta submetido a ginástica laboral sofre interferência de pesos crescentes do cavaleiro, por meio da análise cinemática e cinética do andamento. O critério para inclusão de cavalos ao estudo foi nenhuma claudicação visível, sem sinais ou sintomas compatíveis com lesões musculoesqueléticas, habituados às sessões de equoterapia por três anos e trabalhando regularmente.

Esta seleção resultou na utilização de equinos mestiços, com idade média de 15 anos e peso corporal (PC) médio de $500 \mathrm{~kg}$. Os tratamentos foram compostos pelo arranjo de dois níveis de atividade física (sedentário e ginástica laboral), com três cargas crescentes de peso, representadas pelo cavaleiro, correspondendo a relação cavalo:cavaleiro de 10, 15 e $20 \%$ do peso vivo do cavalo (PVC), conforme ilustrado na figura 12.

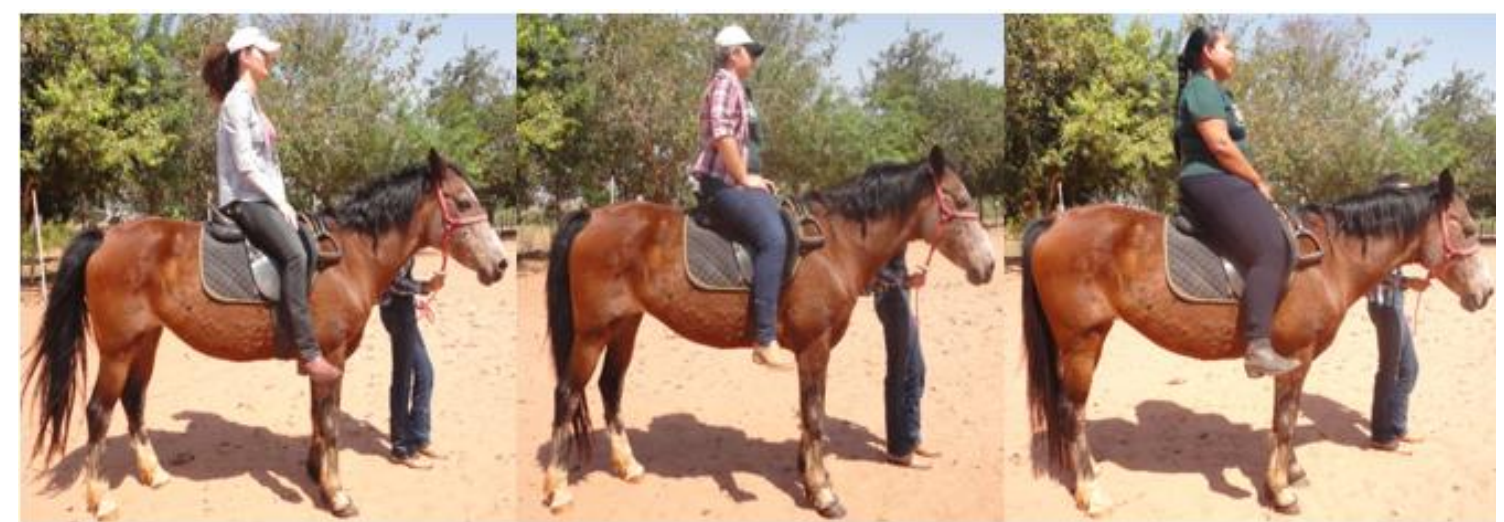

Figura 12. Imagem ilustrativa das cargas crescentes de peso do cavaleiro em relação ao peso do cavalo, da esquerda para direita, representando 15, 20 e $25 \%$ PVC.

Foram mensuradas as variáveis referentes à cinemática, por meio do acelerômetro Equimetrix, como, o comprimento da passada $(\mathrm{CP})$, cadência ou frequência de passada (FP), regularidade (R), simetria (S), bem como as variáveis 
cinéticas (por meio do acelerômetro Equimetrix) de forças de propulsão (FP) e total (FT), para avaliar a qualidade dos andamentos.

Assim, foi observado que no andamento ao passo, a regularidade, simetria e o deslocamento dorso-ventral de cavalos realizando a ginástica laboral, apresentaram incrementos significativos, em relação ao grupo sedentário, sob as mesmas cargas de peso do cavaleiro. Cavaleiros com $25 \%$ PVC, montados em animais submetidos a atividade física tiveram os desempenhos cinemáticos igualados aos cavalos com montarias mais leves e também exercitados. Menor deslocamento dorso-ventral $(\mathrm{P}<0,0203)$ foi observado aos cavalos terapeutas sedentários e com maior carga de peso sobre os mesmos, de $2,43 \mathrm{~cm}$. A cadência não sofreu efeito significativo dos tratamentos (Tabela 10).

Tabela 10 - Valores médios com desvio padrão $( \pm)$ das variáveis cinemáticas do passo de cavalos terapeutas sedentários ou submetidos a ginástica laboral, sob crescentes cargas do cavaleiro em relação ao peso vivo do cavalo (\% PVC).

\begin{tabular}{|c|c|c|c|c|c|c|c|}
\hline \multirow{2}{*}{ Variável } & \multicolumn{3}{|c|}{ Sedentários } & \multicolumn{3}{|c|}{ Ginástica Laboral } & \multirow{2}{*}{$\begin{array}{l}\text { Valor } \\
\text { de P }\end{array}$} \\
\hline & $15 \% \mathrm{PVC}$ & $20 \% \mathrm{PVC}$ & $25 \% \mathrm{PVC}$ & $15 \% \mathrm{PVC}$ & $20 \% \mathrm{PVC}$ & $25 \% \mathrm{PCV}$ & \\
\hline Regularidade $^{1}$ & $96,1 \pm 48,6^{b}$ & $108,3 \pm 31,7^{\mathrm{b}}$ & $108,4 \pm 33,4^{\mathrm{b}}$ & $147,1 \pm 44,4^{\mathrm{a}}$ & $150,7 \pm 38,4^{\mathrm{a}}$ & $141,0 \pm 35,3^{\mathrm{a}}$ & 0,0002 \\
\hline Simetria $^{2}$ & $183,7 \pm 22,6^{\mathrm{c}}$ & $170,8 \pm 31,3^{\mathrm{c}}$ & $175,0 \pm 39,7^{\mathrm{c}}$ & $225,7 \pm 68,8^{\mathrm{ab}}$ & $210,5 \pm 62,1^{\mathrm{ab}}$ & $242,4 \pm 40,1^{\mathrm{a}}$ & 0,0250 \\
\hline Cadência $^{3}$ & $0,94 \pm 0,05$ & $0,95 \pm 0,05$ & $0,91 \pm 0,05$ & $0,92 \pm 0,04$ & $0,92 \pm 0,06$ & $0,91 \pm 0,06$ & 0,6048 \\
\hline $\mathrm{DDV}^{4}(\mathrm{~cm})$ & $2,93 \pm 0,92^{\mathrm{abc}}$ & $2,57 \pm 0,65^{\mathrm{bc}}$ & $2,43 \pm 0,76^{\mathrm{c}}$ & $3,38 \pm 1,02^{\mathrm{ab}}$ & $3,63 \pm 1,54^{\mathrm{a}}$ & $3,50 \pm 1,55^{\mathrm{a}}$ & 0,0203 \\
\hline
\end{tabular}

${ }^{1}$ Regularidade (/200); ${ }^{2}$ Simetria (\%); ${ }^{3}$ Cadência (número de passada/segundo); ${ }^{4} \mathrm{DDV}=$ deslocamento dorso-ventral. ${ }^{\mathrm{a}, \mathrm{b}, \mathrm{c}}$ Médias seguidas de letras diferentes, na linha, diferem entre si pelo teste de Tukey.

A realização da ginástica laboral melhorou a regularidade e o deslocamento dorso-ventral do trote dos cavalos terapeutas, independente do peso do cavaleiro, ou seja, possibilitou aos cavalos com maiores cargas se deslocarem igualmente aos animais 
com montarias mais leves (Tabela 11). Diferentemente, cavalos terapeutas sedentários e montados por cavaleiros contendo $25 \%$ PVC tiveram desempenho cinemático ao trote prejudicado $(\mathrm{P}<0,05)$, obtendo os piores resultados para regularidade, simetria e deslocamento dorso-ventral, entre todos os tratamentos, com valores de 206,1 (/200), $155,1 \%$ e $7,75 \mathrm{~cm}$, respectivamente. A simetria ao trote melhorou significativamente aos cavalos exercitados e com incrementos de peso do cavaleiro até $20 \%$ PVC. Animais submetidos a ginástica laboral e a montaria mais pesada, resultaram na mesma simetria do trote àqueles suportando apenas uma carga de 15\% PVC e sedentários. A cadência não sofreu efeito significativo dos grupos experimentais.

Tabela 11 - Valores médios com desvio padrão $( \pm)$ das variáveis cinemáticas do trote de cavalos terapeutas sedentários ou submetidos a ginástica laboral, sob porcentagens crescentes de carga do cavaleiro em relação ao peso vivo do cavalo (\% PVC).

\begin{tabular}{|c|c|c|c|c|c|c|c|}
\hline \multirow{2}{*}{ Variável } & \multicolumn{3}{|c|}{ Sedentários } & \multicolumn{3}{|c|}{ Ginástica Laboral } & \multirow{2}{*}{$\begin{array}{l}\text { Valor } \\
\text { de P }\end{array}$} \\
\hline & $15 \% \mathrm{PVC}$ & $20 \%$ PVC & $25 \% \mathrm{PVC}$ & $15 \% \mathrm{PVC}$ & $20 \%$ PVC & $25 \% \mathrm{PVC}$ & \\
\hline Regularidade $^{1}$ & $202,6 \pm 38,9^{c}$ & $198,4 \pm 37,3^{\mathrm{c}}$ & $206,1 \pm 52,9^{\mathrm{bc}}$ & $293,3 \pm 23,2^{a}$ & $272,8 \pm 52,5^{\mathrm{a}}$ & $249,3 \pm 47,2^{\mathrm{ab}}$ & 0,0001 \\
\hline Simetria $^{2}$ & $184,9 \pm 37,4^{\mathrm{bc}}$ & $170,2 \pm 35,1^{\mathrm{cd}}$ & $155,1 \pm 18,5^{\mathrm{d}}$ & $220,8 \pm 42,3^{a}$ & $208,9 \pm 35,6^{\mathrm{ab}}$ & $185,2 \pm 40,0^{\mathrm{bc}}$ & 0,0001 \\
\hline Cadência $^{3}$ & $1,44 \pm 0,05$ & $1,41 \pm 0,04$ & $1,35 \pm 0,20$ & $1,38 \pm 0,09$ & $1,39 \pm 0,13$ & $1,36 \pm 0,09$ & 0,3784 \\
\hline $\mathrm{DDV}(\mathrm{cm})$ & $8,71 \pm 1,59^{\mathrm{abc}}$ & $7,92 \pm 1,73^{\mathrm{bc}}$ & $7,75 \pm 1,36^{\mathrm{c}}$ & $9,06 \pm 1,81^{\mathrm{ab}}$ & $8,88 \pm 1,54^{\mathrm{abc}}$ & $9,57 \pm 1,45^{\mathrm{a}}$ & 0,0392 \\
\hline
\end{tabular}

${ }^{1}$ Regularidade (/200); ${ }^{2}$ Simetria (\%); ${ }^{3}$ Cadência (número de passada/segundo); ${ }^{4} \mathrm{DDV}=$ deslocamento dorso-ventral. ${ }^{\mathrm{a}, \mathrm{b}, \mathrm{c}}$ Médias seguidas de letras diferentes, na linha, diferem entre si pelo teste de Tukey.

A propulsão do passo de cavalos terapeutas foi melhorada pela atividade física desenvolvida. Os cavalos mais prejudicados cineticamente, no andamento ao passo, foram os sedentários e carregando maior peso do cavaleiro (Tabela 12). Cavalos sedentários necessitaram de mais força total $(\mathrm{P}<0,049)$ para se deslocarem ao trote. A propulsão do trote não sofreu efeito significativo dos grupos experimentais. (Tabela 13). 
Tabela 12 - Valores médios com desvio padrão $( \pm)$ das variáveis cinéticas do passo de cavalos terapeutas sedentários ou submetidos a ginástica laboral, sob porcentagens crescentes de carga do cavaleiro em relação ao peso vivo do cavalo (\% PVC).

\begin{tabular}{|c|c|c|c|c|c|c|c|}
\hline \multirow{2}{*}{$\begin{array}{l}\text { Variável } \\
\text { (W/kg) }\end{array}$} & \multicolumn{3}{|c|}{ Sedentários } & \multicolumn{3}{|c|}{ Ginástica Laboral } & \multirow{2}{*}{$\begin{array}{l}\text { Valor } \\
\text { de P }\end{array}$} \\
\hline & $15 \% \mathrm{PVC}$ & $20 \%$ PVC & $25 \% \mathrm{PVC}$ & $15 \% \mathrm{PVC}$ & $20 \% \mathrm{PVC}$ & $25 \% \mathrm{PVC}$ & \\
\hline Propulsão & $3,13 \pm 1,08^{\mathrm{bc}}$ & $3,03 \pm 2,15^{\mathrm{abc}}$ & $2,11 \pm 1,33^{\mathrm{c}}$ & $3,51 \pm 0,51^{\mathrm{a}}$ & $3,63 \pm 1,14^{\mathrm{a}}$ & $3,28 \pm 1,09^{\mathrm{ab}}$ & 0,0453 \\
\hline Força Total & $4,96 \pm 2,00$ & $4,74 \pm 2,71$ & $4,07 \pm 2,10$ & $5,42 \pm 2,84$ & $6,06 \pm 1,68$ & $5,2 \pm 1,46$ & 0,3302 \\
\hline
\end{tabular}

Tabela 13 - Valores médios com desvio padrão $( \pm)$ das variáveis cinéticas do trote de cavalos terapeutas sedentários ou submetidos a ginástica laboral, sob porcentagens crescentes de carga do cavaleiro em relação ao peso vivo do cavalo (\% PVC).

\begin{tabular}{|c|c|c|c|c|c|c|c|}
\hline \multirow{2}{*}{$\begin{array}{l}\text { Variável } \\
\text { (W/kg) }\end{array}$} & \multicolumn{3}{|c|}{ Sedentários } & \multicolumn{3}{|c|}{ Ginástica Laboral } & \multirow{2}{*}{$\begin{array}{l}\text { Valor } \\
\text { de P }\end{array}$} \\
\hline & $15 \% \mathrm{PVC}$ & $20 \%$ PVC & $25 \% \mathrm{PVC}$ & $15 \% \mathrm{PVC}$ & $20 \%$ PVC & $25 \% \mathrm{PVC}$ & \\
\hline Propulsão & $9,43 \pm 2,94$ & $11,51 \pm 4,22$ & $11,29 \pm 5,28$ & $13,51 \pm 6,39$ & $13,38 \pm 5,17$ & $16,69 \pm 7,21$ & 0,1016 \\
\hline Força Total & $42,71 \pm 27,1^{\mathrm{ab}}$ & $39,68 \pm 24,0^{\mathrm{b}}$ & $39,32 \pm 15,0^{\mathrm{b}}$ & $25,12 \pm 8,4^{\mathrm{c}}$ & $28,75 \pm 12,7^{\mathrm{bc}}$ & $29,08 \pm 13,8^{\mathrm{bc}}$ & 0,0490 \\
\hline
\end{tabular}

${ }^{a, b, c}$ Médias seguidas de letras diferentes, na linha, diferem entre si pelo teste de Tukey.

Inexistem pesquisas avaliando o efeito da realização de ginástica laboral em cavalos sobre o máximo de peso do cavaleiro que o mesmo pode suportar, sem provocar mudanças deletérias na cinemática e cinética dos andamentos. Contudo há na literatura métodos de avaliação envolvendo peso adicional a sela, mas sem o envolvimento de atividade física para fortalecimento muscular. Deve-se ressaltar que adição de peso ao cavalo é considerado como peso morto e que não necessariamente se equivale ao peso vivo, pois o cavaleiro pode ajustar seu equilíbrio e técnica para diminuir o seu impacto sobre o cavalo (GREVE \& DYSON, 2013). Para obter resultados com representação mais realística do que ocorre quando cavaleiros de vários pesos montam os cavalos, escolheu-se trabalhar com cavaleiros de diferentes pesos do que adicionar peso morto. 
Neste ensaio tomou-se o cuidado em que todas avaliações performadas ao trote, fossem realizadas na modalidade "elevado", devido ao objetivo de monitoramento biomecânico. Sabe-se que há diferenças significativas na simetria em cavalos montados no trote elevado ou sentado (PERSSON-SJODIN et al. 2018). Assim, orientou-se aos cavaleiros para trotarem elevado e na mesma diagonal, reduzindo potencialmente as inconsistências entre os cavaleiros.

Com respeito a sela, optou-se em utilizar o mesmo equipamento para todos os cavalos, evitando-se introduzir outro fator de variação. Ainda, apesar do nível máximo de peso do cavaleiro estudado, corresponder a $25 \%$ PVC, necessitou-se que cada cavalo fosse montado por apenas um minuto/avaliação, para gravação dos dados biomecânicos. Desta forma, considerou-se todos os cavalos terapeutas aptos fisicamente para desempenhar este trabalho.

Um passo de boa qualidade, em cavalos treinados, deve apresentar-se regular, similar, com bom deslocamento dorso-ventral, sem modificações na cadência (BIAU e BARREY, 2004b; OLIVEIRA et al., 2018). Os resultados mostrados da tabela 10 encontram-se concordantes a estes propósitos, no qual os cavalos submetidos a ginástica laboral obtiveram os melhores valores a estas variáveis, incluindo-se os animais montados por cavaleiros pesados (25\% PVC). Oliveira et al. (2015), também observaram incrementos significativos na qualidade do movimento do passo em cavalos terapeutas, não montados e submetidos a ginástica laboral. Corroborativamente, os dados observados na tabela 1 para a regularidade de 150,7 (/200) e deslocamento dorso ventral $(3,63 \mathrm{~cm})$ para animais exercitados e com cavaleiro pesando $20 \%$ PV foram próximos aos encontrados para cavalos de adestramento de raça alemã de 152 (/200) e 4,3 cm, respectivamente (BARREY et al., 2002). 
Oliveira et al. (2019), trabalhando com cavalos terapeutas, em avaliações não montadas e submetidos a ginástica laboral, realizada na frequência de nenhuma à quatro vezes/semana, também encontraram benefícios biomecânicos sobre o andamento ao trote. Observaram ganhos da REG e SIM $(\mathrm{P}<0,05)$, em que os melhores resultados foram encontrados aos cavalos submetidos a ginástica laboral realizada de três à quatro vezes/semana, com valores de 15,4 e 16,0 (/200) para REG e de 14,9 e 20,6 (\%) para SIM, respectivamente. Concluiu-se que a realização de ginástica laboral em cavalos terapeutas, a partir de três sessões semanais, melhora o movimento tridimensional do trote, devido ao ganho na regularidade e simetria, mantendo-se a mesma cadência de passada. Adicionalmente, os resultados cinemáticos para o trote de cavalos submetidos a ginástica laboral (Tabela 6), mostraram-se bem próximos às regras da Federação Equestre Internacional (BARREY et al., 2002), contendo alta regularidade, acima de 300 (/200), baixa cadência (< 1,4 passadas/segundo) e elevado deslocamento dorsoventral $(>10 \mathrm{~cm})$.

Muitas pesquisas têm demonstrado mudanças no andamento em associação a adição de peso (MATSUURA et al., 2013a,b; MATSUURA et al., 2016; GUNNARSSON et al., 2017) em relação a cavaleiros de diferentes pesos. Em estudo com oito cavalos islandeses, ao trote e carregando 20, 25, 30 e 35\% PVC (único cavaleiro profissional mais adição de peso), avaliaram a cinemática por meio de câmeras de alta velocidade e em um teste de exercício incremental. Diferentemente, encontraram que o aumento do peso de cavaleiro foi associado com decréscimos na cadência e no comprimento da passada, sendo que a última variável não foi monitorada neste ensaio. A avaliação da simetria, regularidade e cadência dos andamentos ao passo e trote de cavalos e pôneis nativos do Japão, carregando peso total de $80-130 \mathrm{~kg}(24-$ $38 \%$ PVC) e $70-120 \mathrm{~kg}(30-52 \%$ do PVC), respectivamente, foi objeto de estudo por 
Matsuura et al. (2013a,b). Os cavalos nativos japoneses, a simetria do trote para $100 \mathrm{~kg}$ foi inferior ao grupo de $80 \mathrm{~kg}$. Concluíram que a carga máxima permissível deveria ser inferior a $100 \mathrm{~kg}$, ou seja, < 29\% do PVC. Aos pôneis a cadência do andamento diminuiu com os cavaleiros mais pesados, concluindo que a carga máxima permissível deveria ser inferior a $100 \mathrm{~kg}$, ou seja, < 43\% do PVC.

Dyson et al. (2019), desenvolveram uma pesquisa visando determinar o efeito do peso do cavaleiro sobre o andamento de cavalos em trabalho regular de equitação. Cada animal foi montado por cavaleiros classificados como leve, moderado, pesado e muito pesado, correspondendo aos valores médios da relação cavaleiro:cavalo de 10,0-11,7\%, 12,8-15,0\%, 15,3-17,9\% e 23,6-27,5\% do PVC. A avaliação do andamento foi mensurada determinando-se a simetria do trote subjetivamente (escore clínico) e objetivamente (sensor inercial). Encontraram assimetria no trote nos cavalos montados por cavaleiros pesados e muito pesados, em ambos métodos. Concluíram que cavaleiros grandes podem induzir, temporariamente, claudicação nos cavalos, consistente com dor musculoesquelética.

Deve-se lembrar que os autores supracitados (MATSUURA et al., 2013a,b e DYSON et al., 2019), trabalharam com cavalos que não foram submetidos a atividade física de suporte à musculatura de sustentação do dorso, como é o caso da ginástica laboral realizada nos cavalos do atual ensaio. Assim, era esperado que os resultados entre as pesquisas fossem divergentes, pois os cavalos terapeutas exercitados e carregando 15, 20 ou 25\% PVC, não resultaram em decréscimos aos mesmos parâmetros cinemáticos estudados. Contudo, o comportamento de resposta encontrado por Matsuura et al. (2013a,b) e Dyson et al. (2019), foi verificado no grupo de cavalos terapeutas sedentários e com acréscimo da carga de peso do cavaleiro (Tabelas 10 e 11). 
A ginástica laboral foi desenvolvida com o objetivo de fortalecer a musculatura do core, envolvendo os músculos multifídus, abdominais e íliopsoas. Isto pode justificar os bons resultados alcançados sobre a biomecânica dos cavalos, mesmo quando montados por cavaleiros pesados. Pesquisadores têm identificado aumento na extensão da região toracolombar de cavalos montados vs não-montados em todos andamentos, devido à diferença de carga colocada sobre os mesmos (de COCQ et al., 2004).

Uma suave extensão dorsal provoca aproximação dos processos espinhosos das vértebras localizadas no segmento toracolombar (FABER et al., 2000), além de menor amplitude de movimento da região lombossacral, (GÓMEZ ÁLVAREZ et al., 2008). Tais condições estão relacionadas com disfunções na toracolombar, no qual o cavalo mantém seu dorso endurecido quando montado (GREVE \& DYSON, 2013). Isto torna mais difícil para o cavaleiro absorver o movimento do cavalo e, consequentemente, mais tensão e impacto na área, atrofiando a musculatura epaxial, enfraquecimento potencial da coluna, com a instalação de um círculo vicioso (GREVE et al., 2017).

Portanto, o fortalecimento da musculatura, que suporta a coluna do cavalo, é imprescindível aos cavalos terapeutas montados por cavaleiros grandes. Já que pesquisas têm identificado a hipertrofia do músculo multifidus em cavalos submetidos a ginástica laboral (OLIVEIRA et al., 2015) e aos exercícios de mobilização dinâmica (STUBBS et al., 2011), um dos componentes da ginástica laboral.

Os valores cinéticos do andamento ao passo e trote obtidos em cavalos submetidos a ginástica laboral (Tabelas 12 e 13), encontram-se semelhantes aos resultados encontrados na literatura consultada, para cavalos de diferentes raças (BIAU et al. 2002; WEISHAUPT et al., 2006; LÓPEZ-SANROMÁN et al., 2012). Diferentemente, observou-se elevados valores de força total para cavalos terapeutas 
sedentários (Tabela 9), para todas cargas de cavaleiro, implicando que cavalos com índices insatisfatórios na regularidade e simetria, movimentam-se cineticamente com pouca eficiência. A deficiência de artigos científicos abordando a atual temática, em termos cinéticos, limitam a discussão dos resultados.

O peso do cavaleiro tem sido associado com incremento de força sobre o cavalo (de COCQ et al., 2006; de COCQ et al., 2009). Na presente pesquisa não foi possível verificar este tipo de comportamento de resposta em relação ao grupo experimental submetido a ginástica laboral. Os dados demonstraram ausência de interferência do peso do cavaleiro sobre os parâmetros cinéticos, bem como um processo de economia de energia nos andamentos ao passo e trote, denotando melhor função ergonômica durante a locomoção (Tabelas 12 e 13).

O aumento de carga sobre o dorso do cavalo pode ainda ocasionar uma redistribuição do centro de gravidade do cavalo, mais proximalmente aos membros torácicos, o que justifica o aumento de claudicações observadas nos animais destes ensaios (MATSUURA et al., 2013a,b e DYSON et al., 2019). Contudo, devido aos elevados índices cinemáticos mantidos pela execução da ginástica laboral (Tabelas 10 e 11), pode-se inferir que os cavalos terapeutas conseguiram evitar este deslocamento do centro de gravidade, tornando-os mais equilibrados.

Ainda, a velocidade de deslocamento é um importante fator no aumento de força gerado pelo cavalo (de COCQ et al., 2006; de COCQ et al., 2009). Esta constatação foi verificada em todos os grupos experimentais, no qual o passo foi desenvolvido a uma velocidade de $1,3 \mathrm{~m} / \mathrm{s}$ e o trote à $8 \mathrm{~m} / \mathrm{s}$, geraram incrementos na força de propulsão e força total (Tabelas 8 e 9). Sendo assim, o principal resultado deste estudo consiste na validação de que a ginástica laboral influencia positivamente a cinemática e cinética de 
cavalos terapeutas montados por cavaleiros pesados, como o correspondente a $25 \%$ do PVC.

Na comunidade equestre tem crescido as discussões sobre os tamanhos relativos entre cavaleiro e cavalo. Há indícios que inapropriado tamanho do cavaleiro possui implicações para o bem-estar dos cavalos, mas com poucas validações científicas que forneçam evidências, para servirem como guia básico de boas condutas na equitação. Entende-se que este assunto é multifatorial, com inter-relações entre os fatores, incluindo a idade do cavalo, condição física, desenvolvimento muscular, musculatura de suporte à coluna, comprimento da região toracolombar, habilidade do cavaleiro, bem como o ajuste de sela para o cavalo e cavaleiro (CLAYTON et al., 2015).

A regularidade e simetria são importantes índices de claudicação em cavalos (LÓPEZ-SANROMÁN et al., 2012; DYSON et al., 2019), sendo assim, comprovou-se que animais submetidos a ginástica laboral e montados por cavaleiros grandes mantiveram-se hígidos, permanecendo regulares e simétricos nos andamentos ao passo e trote (Tabelas 10 e 11). Neste sentido, o presente trabalho traz contribuições científicas importantes no tocante a questão do tamanho do cavaleiro em relação ao cavalo, por ter revertido os efeitos deletérios causados pela montaria pesada sobre a biomecânica de cavalos terapeutas. Podendo-se recomendar aos cavalos, de cavaleiros grandes, a execução da ginástica laboral, para que permaneçam saudáveis. 


\section{CONCLUSÕES}

A partir desta vasta revisão científica pode-se concluir que a realização de ginástica laboral em cavalos terapeutas, realizada em três sessões semanais, melhora:

- a cinemática ao trote, devido ao ganho na regularidade e simetria, mantendose a mesma cadência de passada;

- a cinemática do passo, incrementando a qualidade deste andamento;

- o movimento tridimensional no passo e trote, produzindo mais força e com maior amplitude de deslocamento nos três vetores do movimento;

- a hipertrofia do musculus multifidus, que fornece sustentação à coluna;

- a capacidade de suporte do dorso em carregar cavaleiros pesados, tornando os andamentos mais regulares e simétricos, bem como cineticamente eficiente.

Desta forma, a ginástica laboral para cavalos terapeutas, pode se tornar uma importante ferramenta de reabilitação aos programas de equoterapia. 


\section{REFERÊNCIAS BIBLIOGRÁFICAS}

ALEMAN, M. A review of equine muscle disorders. Neuromuscular disorders, v. 18, n. 4, p. 277-287, 2008.

ALLEN, A. K.; JOHNS, S.; HYMAN, S. S.; SISLAK, M. D.; DAVIS, S.; AMORY, J. How to diagnose and treat back pain in the horse. In: AAEP Proceedings, Vol. 56, p. 384-388, 2010.

ALLENDER, S.; COWBURN, G.; FOSTER, C. Understanding participation in sport and

physical activity among children and adults: a review of qualitative studies, Comparative

Exercise v.21, n.6, p.826-835, 2006.

ALVAREZ, C. G; L'AMI, J. J.; MOFFATT, D.; BACK, W.; VAN WEEREN, P. R. Effect of chiropractic manipulations on the kinematics of back and limbs in horses with clinically diagnosed back problems. Equine Veterinary Journal, v. 40, n. 2, p. 153$159,2008$.

ALVES, A. L. G.; DA FONSECA, B. P. A.; THOMASSIAN, A.; DE MELLO NICOLETTI, J. L.; HUSSNI, C. A.; DA SILVEIRA, A. B. Lombalgia em eqüinos. Brazilian Journal of Veterinary Research and Animal Science, p. 191-199, 2007.

ALVES, A. L. G. Semiologia do sistema locomotor de equinos. Semiologia veterinária: a arte do diagnóstico, v. 2, p. 516-551, 2008.

ANDERSON, K. B.; ANDERSON, C. A.; DILL, K. E.; DEUSER, W. E. The interactive relations between trait hostility, pain, and aggressive thoughts. Aggressive Behavior, v. 24, p. 161-171, 1998.

ANDERSON, C. A.; ANDERSON, K. B.; DORR, N.; DENEVE, K. M.; FLANAGAN, M. Temperature and aggression. Advances in Experimental Social Psychology, v. 32, p. 63-133, 2000.

ANDRADE, A. M. Biometria e locomoção de equinos da raça brasileiro de hipismo. Dissertação de mestrado. Universidade Federal Rural do Rio de Janeiro, Seropédica - Rio de Janeiro. 2014.

ANDRIOLI, A.; BRITO, I. F. Bem-estar e produção animal. Embrapa Caprinos e Ovinos. Documentos, p. 9-25, 2009. 
ARAÚJO, T.B. et al. Effects of hippotherapy on mobility, strength and balance in eldery. Archives of Gerontology and Geriatrics, v.56, p.478-481, 2013.

ARRUDA, A.H. et al. Determinação da rotação de garupa através de parâmetros biomecânicos dos cavalos como medida indireta da rotação de cintura em praticantes. In... XII Congresso Brasileiro de Equoterapia. Brasília, p.189-193, 2006.

BACK, W.; CLAYTON, H. Equine locomotions. Washington: Saunders, 2013. 528p.

BIKNEVICIUS, A. R.; MULLINEAUX, D. R.; CLAYTON, H. M. Ground reaction forces and limb function in tölting Icelandic horses. Equine Veterinary Journal, v. 36, n. 8, p. 743-747, 2004.

BARREY et al. Early evaluation of dressage ability in different breeds. Equine Vet. J., v. 34, p. 319-324, 2002.

BENDA, W. et al. Improvements in muscle symmetry in children with cerebral palsy after equine assited therapy (hippotherapy). The Journal of Alternative and Complementary Medicine, v.9, n.6, p.817-825, 2003.

BIAU, S. et al. The effect of rein on kinetic variables of locomotion. Equine Vet. J., v. 34, p. 359-362, 2002.

BIAU, S.; BARREY, E. The trot characteristics during the first years of dressage training. Pferdeheikunde, v.20, p. 1-4, 2004a.

BIAU, S.; BARREY, E. Relationship between stride characteristics and score in dressage tests. Pferdeheikunde, v.20, p. 1-4, 2004b.

BOBBERT, M. F.; SANTAMARÍA, S.; VAN WEEREN, P. R.; BACK, W.;

BARNEVELD, A. Can jumping capacity of adult show jumping horses be predicted on the basis of submaximal free jumps at foal age? A longitudinal study. The Veterinary Journal, v. 170, p. 212-221, 2005.

BROOM, D. M. Indicators of poor welfare. British Veterinary Journal, v. 142, n. 6, p. 524-526, 1986.

BROOM, D. M.; MOLENTO, C. F. M. Bem-estar animal: conceito e questões relacionadas revisão. Archives of Veterinary Science, v. 9, n. 2, p. 1-11, 2004.

BROOM, D. M.; FRASER, A. F. Domestic animal behaviour and welfare. Cabi, cap. 6, p. 68-69, 2015. 
BURLA. J. B.; OSTERTAG. A.; WESTERATH. H. S; HILLMANN. E. Gait determination and activity measurement in horses using an Accelerometer. Computers and Electronics in Agriculture, v. 102, p.127-133, 2014.

BYSTRÖM, A.; RHODIN, M.; VON PEINEN, K.; WEISHAUPT, M. A.; ROEPSTORFF, L. Basic kinematics of the saddle and rider in high-level dressage horses trotting on a treadmill. Equine Veterinary Journal, v. 41, n. 3, p. 280-284, 2009.

CANO, M.R. et al. Kinematic characteristics of Andalusian, Arabian and AngloArabian horses: a comparative study. Research in Veterinary Science, v.71, p.147$153,2001$.

CHAMPAGNE, D.; DUGAS, C. Improving gross motor function and postural control with hippotherapy in children with Down syndrome: Case reports. Physiotherapy Theory and Practice, v.1, p.1-8, 2010.

CHIROLLI, M. J.; PANIZ, V. L. F.; QUINTEIRO, S. C. EQUOTERAPIA: alterações de diferentes estímulos causadas pela variação na amplitude e frequência do passo do cavalo. FICE. Instituto Federal Catarinense Campus Camboriú, p. 45-51. 2015.

CLAYTON, H.M. Gait evaluation: making the most of your home video system. Proc. Am. Ass. Equine Practners. V. 36, p.447-455, 1990.

CLAYTON, H. M. Conditioning Sports Horses. Mason: Sport Horse Publ., 1991. p.271.

CLAYTON, H.M. Comparison of the stride kinematics of the collected, medium, and extended walks in horses. American Journal of Veterinary Research, v.56, n.7, p.849-

$852,1995$.

CLAYTON, H.M.; LANOVAZ, J.L.; SCHAMHARDT, H.C; van WESSUM, R. The effects of a rider's mass on ground reaction forces and fetlock kinematics at the trot. Equine vet. J., Suppl. 30, 218-221. 1999.

CLAYTON, H.M.; SCHAMHARDT, H.C. Measurement techniques for gait analysis. In: BACK, W.; CLAYTON, H.M. Equine Locomotion. London: W.B. Saunders, 2001. Cap. 3, p.55-76.

CLAYTON, H. M. The dynamic horse. Mason: Sport Horse Publications, 2004. 265p.

CLAYTON, H.M.; KAISER, L.J., LAVAGNINO, M. Dynamic mobilizations in cervical 
flexion: effects on intervertebral angulations. Equine Veterinary Journal, v.42, n.s38, p.688-694, 2010.

CLAYTON, H.M. et al. Center of pressure movements during equine assisted activities. The American Journal of Occupational Therapy, v.65, n.2, p.211-216, 2011.

CLAYTON, H.M.; LARSON, B.; KAISER, L.A.J.; LAVAGNINO. M. Length and elasticity of side reins affect rein tension at trot. The Veterinary Journal, v.188, n., p.291-294, 2011.

CLAYTON, H. M.; KAISER, L. J.; LAVAGNINO, M.; STUBBS, N. C. Evaluation of intersegmental vertebral motion during performance of dynamic mobilization exercises in cervical lateral bending in horses. American journal of veterinary research, v. 73, n. 8, p. 1153-1159, 2012.

CLAYTON, H.; DYSON, S.; HARRIS, P.; BONDI, A. Horses and riders: applying the science. Equine Veterinary Education. 27,447-452. 2015.

CLAYTON, H. M. Core training and rehabilitation in horses. Veterinary Clinics: Equine Practice, v. 32, n. 1, p. 49-71, 2016.

COCQ, P.; van WEEREN,P.R.; BACK, W. Effects of girth, saddle and weight on movements of the horse. Equine Veterinary Journal. 36, 758- 763. 2004.

COCQ, P.; PRINSEN,H.; van WEEREN,P.R; BACK,W. Saddle pressure measuring: Validity, reliability and power to discriminate between different saddle- fits. Equine Veterinary Journal, 172, 265-273. 2006.

COCQ, P. et al. Usability of normal force distribuition measurements to evaluate asymmetrical loading of the back of the horse and different rider positions on a standing horse. The Veterinary Journal, v.181, p.266-273, 2009.

COCQ, P. et al. Vertical forces on the horses back in sitting and rising trot. Journal of Biomechanics, v.43, p.627-631, 2010.

COTTRIALL, S; RITRUECHAI P.; WAKELING, J. M. The effects of training aids on the longissimus dorsi in the equine back. Comparative Exercise Physiology, v.3-4 n.5, p. 111-114, 2009.

DANTAS, E.H.M. Alongamento e flexionamento. Rio de Janeiro: Shape, 2005.

D'ANGELIS, F. H.; MOTA, M. D.; FREITAS, E. V.; FERRAZ, G. C.; ABRAHÃO, A. R.; LACERDA-NETO, J. C.; QUEIROZ-NETO, A. Aerobic training, but not creatine, 
modifies longissimus dorsi muscle composition. Journal of Equine Veterinary Science, v. 27 , n. 3 , p. 118-122, 2007.

DEUK KANG, O. et al. Comparative analyses of rider position according to skill levels during wlak and trot in jeju horse. Human Movement Science, v.29, p.956-963, 2010.

DVORAKOVA, T. et al. The influence of the leader on the movement of the horse in walking during repeated hippotherapy sessions. Acta University Palacki. Olomuc. Gymn., v.39, n.3, p.43-50, 2009.

DYCE, K. M.; WENSING, C. J. G.; SACK, W. O. Tratado de anatomia veterinária. São Paulo: Elsevier Brasil, 2004. 813p.

DYSON, S.; GREVE, L. Saddle and girths: what is new? The Veterinary Journal, 207, 73- 79. 2016.

DYSON, S.; ELLIS, A.D.; MACKECHNIE- GUIRE, R.; DOUGLAS, G.; BONDI, A.; HARRIS, P. The influence of rider: horse bodyweight ratio and rider-horse-saddle fit on equine gait and behavior: A pilot study. Equine Veterinary Journal Education. 2019.

EL-MENIAWY, G.H.; THABET, N.S. Modulation of back geometry in children with spastic diplegic cerebral palsy via hippotherapy training. The Egyptian Journal of Medical Human Genetics, v. 13, p.63-71, 2012.

ENCHEFF, J.L. et al. Hippotherapy effects on trunk, pelvic and hip motion during ambulation in children with neurological impairments. Pediatric Physical Therapy, v. 24, p. 242-250, 2012.

FABER, M. et al. Basic three-dimensional kinematics of the vertebral column of horses walking on a treadmill. American Journal Veterinary Research, v.61, n.4, p.399-406, 2000 .

FERLINI, G.M.S.; CAVALARI, N. Os benefícios da equoterapia no desenvolvimento da criança com deficiência física. Caderno multidisciplinar de pós-graduação da UCP, v.1, n.4, p.1-14, 2010.

FOLEY, A. et al. Does hydrotherapy improve strength and physical function in patients with osteoarthritis - a randomized controlled trial comparing a gym based and a hydrotherapy based strengthening programme, v.62, p.1162-1167.

FONSECA, B. P. A.; ALVES, A. L. G.; NICOLETTI, J. L. M.; THOMASSIAN, A.; HUSSNI, C. A.; MIKAIL, S. Thermography and ultrasonography in back pain diagnosis of equine athletes. Journal of Equine Veterinary Science, v. 26, p. 507-516, 2006. 
FRASER, D. Assessing animal well-being: common sense, uncommon science. Food Animal Wellbeing, p. 37-54, 1993.

FUREIX, C.; MENGUY, H.; HAUSBERGER, M. Partners with bad temper: reject or cure? A study of chronic pain and aggression in horses. Plos One, v. 5, n. 8, p. 124-134, 2010 .

GALVÃO, M.I. et al. Effects of a labor gym program in mental workload of workers from rectory of UNIOESTE., v.41, p.5536-5339.

GETTY, R. Anatomia dos animais domésticos. Guanabara - RJ, v. 1, 5 ed., 1986. 1138 p.

GOFF, L. M. Manual Therapy for the Horse-A Contemporary Perspective. Journal of Equine Veterinary Science, v. 29, n. 11, p. 799-808, 2009.

GOFF, L. M. Animal physiotherapy: assessment, treatment and rehabilitation of animals. John Wiley \& Sons, cap. 2, p. 3-12, 2016. 378p.

GÓMEZ ALVAREZ, C.B.; RHODIN, M.; BOBBERT, M.F. The effect of head and neck

position on the thoracolumbar kinematics in the unridden horse. Equine Veterinary Journal, v. 36, n. s36, p.445-451, 2006.

GOMEZ ALVAREZ, C. B. The biomechanical interaction between vertebral column and limbs in the horse: A kinematical study. Tese, Utrecht University, 2007.

GÓMEZ ALVAREZ, C.B. et al. The effect of induced forelimb lameness on thoracolumbar kinematics during treadmill locomotion. Equine Veterinary Journal, v.39, n.3, p.197-201, 2007.

GÓMEZ ÁLVAREZ, C.B.; WENNERSTRAND, J.; BOBBERT, M.F.; LAMERS, L.; JOHNSTON, C.; BACK, W.; van WEEREN, P.R. The effect of induced hindlimb lameness on thoracolumbar kinematics during treadmill locomotion. Equine Veterinary Journal 40,147-152. 2008.

GÓMEZ ALVAREZ, C.B. et al. Back kinematics of healthy trotting horses during treadmill versus over ground locomotion. Equine Veterinary Journal, v.41, n.3, p.297-300, 2009.

GONTIJO, A. L.; CASSOU, F.; MICHELOTTO JUNIOR, P. V.; ALVES, G. E. S.; BRINGEL, B.; RIBEIRO, R. M.; FALEIROS, R. R. Bem-estar em equinos de policiamento em Curitiba/PR: indicadores clínicos, etológicos e ritmo circadiano do cortisol. Ciência Rural, v. 44, n. 7, p. 1272-1276, 2014. 
GUIRRO, E. C. B. P.; HILGERT, A. R.; MARTIN, C. C. Tratamento fisioterapêutico em equino com deslocamento de vértebras cervicais secundário a traumatismo: relato de caso. Revista Portuguesa de Ciências Veterinárias, p. 105-109, 2012.

GROESEL, M. et al. A preliminary model study of the equine back including activity of longissimus dorsi. Equine Veterinary Journal, v.42, n.s38, p.401-406, 2010.

GREVE, L.; PFAU, T.; DYSON, S. Thoracolumbar movement in sound horses trotting in straight lines in hand and on the lunge and the relationship with hind limb symmetry or asymmetry. The Veterinary Journal, 220, 5-104. 2017.

GUNNARSSON, V.; STEFÁNSDÓTTIR, G.J.; JANSSON, A.; ROEPSTORFF,L . The effect of rider weight and additional weight in Icelandic horses in tolt: part II. Stride parameters responses. The Animal Consortium 11, 9, 1567-1572. 2017.

HIGGINS, G. Pilates and stretching. 1. ed. Cincinnati: Horse Inside Out Publicatin. 2009a. 26p.

HACHL, V. et al. Influence of hippotherapy on the kinematics and functional performance of two children with cerebral palsy. Pediatric Physical Therapy, v. 11, p. 89-101, 1999.

HAKANSON, M. et al. The horse as the healer - A study in patients with back pain. Journal of Bodywork and Movement Therapies, v.13, p.43-52, 2009.

HANSON, R.R.; SMALLEY,L.R.; HUFF, G.K.; WHITE, S.; HAMMAD, T.A. Oral treatment with a glucosamine-chondroitin sulfate compound for degenerative joint disease in horse: 25 cases. Equine Practice, v.19, p.16-20, 1997.

HAUSSLER, K.K.; HILL, A.E.; PUTTLITZ, C.M. Effects of vertebral mobilization and

manipulation on kinematics of the thoracolumbar region. American Journal of Veterinary Research, v.68, n.5, p.508-516. 2007.

HAUSSLER, K. K. Review of manual therapy techniques in equine practice. Journal of Equine Veterinary Science, v. 29, n. 12, p. 849-869, 2009.

HAUSSLER, K. K. The role of manual therapies in equine pain management.

Veterinary Clinics: Equine Practice, v. 26, n. 3, p. 579-601, 2010.

HAUSSLER, K. K. Joint Mobilization and Manipulation for the Equine Athlete.

Veterinary Clinics: Equine Practice, v. 32, n. 1, p. 87-101, 2016. 
HENSON, M. D. Equine back patology: diagnosis and tratament. John Wiley \& Sons Ltd, 2009, 420p.

HIDES, J.; GILMORE, C.; STANTON, W.; BOHLSCHEID, E. Multifidus size and symmetry among chronic LBP and healthy asymptomatic subjects. Manual therapy, $v$. 13, n. 1, p. 43-49, 2008.

HIGGINS, G. How your horse moves. 1. ed. Cincinnati: David \& Charles Book. 2009. $153 \mathrm{p}$.

HIGGINS, G.; MARTIN, S. Horse Anatomy for Performance. David \& Charles, 2012, 160p.

HILL, C.; CROOK, T. The relationship between massage to the equine caudal hindlimb muscles and hindlimb protraction. Equine Veterinary Journal, v. 42, p. 683-687, 2010.

HINCHCLIFF, K. W.; KANEPS, A. J.; GEOR, R. J. Equine exercise physiology: The science of exercise in the athletic horse. Elsevier Health Sciences, 2008, 456p.

HOBBS, S.J. et al. Motion analysis and its use in equine practice and research. Veterinary Medicine Austria, v.97, p.55-64, 2010.

HODGSON, D. R.; MCKEEVER, K. H.; MCGOWAN, C. M. The athletic horse: principles and practice of equine sports medicine. Elsevier Health Sciences, p. 36, 2014. 404p.

JANURA, M. et al. A assessment of the pressure exerted by a raider on tack back of horse during hippotherapy. Human Movement Science, v.28, p.387-393, 2009.

JANURA, M. et al. The influence of walking speed on equine back motion in relation to hippotherapy. Veterinary Medicine Austria, v.97, p.1-5, 2010.

JOHNSTON, C. et al. Kinematic evaluation of the back in fully functioning riding horses. Equine Veterinary Journal, v.36, n.6, p.495-498, 2004.

KANEPS, A. J. Practical rehabilitation and physical therapy for the general equine practitioner. Veterinary Clinics: Equine Practice, v. 32, n. 1, p. 167-180, 2016.

KAWANO, M.M. et al. Comparação da fadiga eletromiográfica dos músculos paraespinhais e da cinemática angular da coluna entre indivíduos com e sem dor lombar. Revista Brasileira de Medicina Esportiva, v.14, n.3, p.209-214, 2008. 
KLEIN, B. G. Cunningham tratado de fisiologia veterinária. 5. ed. São Paulo: Elsevier Brasil, 2014. 624p.

KÖNIG, H. E.; LIEBICH, H. G. Anatomia dos Animais Domésticos-: Texto e Atlas Colorido. 4. ed. Belo Horizonte: Artmed Editora, 2016. 610p.

LANDMAN, M. A. A. M.; DE BLAAUW, J. A.; HOFLAND, L. J.; VAN WEEREN, P. R. Field study of the prevalence of lameness in horses with back problems. Veterinary Record, v. 155, p. 165-168, 2004.

LILJEBRINK, Y.; BERGH, A. Goniometry: is it a reliable tool to monitor passive joint range of motion in horses? Equine Veterinary Journal, v. 42, p. 676-682, 2010.

LINDNER, A.; SIGNORINI, R.; VASSALLO, J.; TOMATIS, F. Reproducibility and repeatability of equine muscle thickness measurements with ultrasound. Journal of Equine Veterinary Science, v.30, n.11, p.635-640, 2010.

LÓPEZ-SANRÓMAN, F.J. et al. Gait analysis using 3D accelerometry in horses sedated with xylazine. The veterinary Journal, v.193, p. 212-216, 2012.

MACIEL, R.H. Ergonomia e lesões por esforço repetitivo. Revista da Associação Brasileira para Prevenção de Acidentes, junho/fevereiro, 1994.

MAIA, A. P. A.; SARUBBI, J.; MEDEIROS, B. B. L.; DE MOURA, D. J.

Enriquecimento ambiental como medida para o bem-estar positivo de suínos. Revista

Eletrônica em Gestão, Educação e Tecnologia Ambiental, v. 14, n. 14, p. 2862-2877, 2013.

MAcPHAIL, H.E.A. et al. Trunk postural reactions in children with and without cerebral palsy during therapeutic horseback riding. Pediatric Physical Therapy, v. 10, p. 143-147, 1998.

MARTIN, P.; CHEZE, L.; POURCELOT, P.; DESQUILBET, L.; DURAY, L.; CHATEAU,H. Effects of the rider on the kinematics of the equine spine under the saddle during the trot using inertial measurement units: Methodological study and preliminary results. The Veterinary Journal 221, 6-10. 2017.

MATSUURA, A.; IRIMAJIRI,M.; MATSUZAKIK.; HIRAGURI, Y.; NAKANOWATARI,T.; YAMAZAKI,A.; HODATE,K. Method for estimating maximum permissible load weight for Japanese native horses using accelerometerbased gait analysis. Journal Animal Science. 84 , 75-81. 2013a 
MATSUURA, A; SAKUMA, S; IRIMAJIRI, M; HODATE, K. Maximum permissible load weight of Taishuh pony at a trot. American Society of Animal Science, 91, 39893996. 2013b

MATSUURA,A.; $\quad$ IRIMAJIRI,M.; $\quad$ MATSUZAKI,K.; $\quad$ HIRAGURI,Y.; NAKANOWATARI,,T.; YAMAZAKI,A.; HODATE,K. Method for estimating maximum permissible load weight for Japanese native horses using accelerometerbased gait analysis. Animal Science Journal, v 84, p 75-81, 2013.

MATSUURA, A; MANO, H.; IRIMAJIRI, M.; HODATE, K. Maximum permissible load for Yonaguni ponies (Japanese landrace horses) trotting over a short, straitht course. Anim welf. 25, 151- 156. 2016.

MATSUURA, A.; INOUE, S.; IRIMAJIRI, M.; HODATE, K.. Maximum permissible load for Kiso horses trotting over a short, straight course. Animal Science Journal 89, 232-236. 2018.

McGIBBON, N.H. et al. Immediate and long term effects of hyppotherapy on symmetry of adductor muscle activity and functional ability in children with spastic cerebral pasly.

Archives Physical Medicine Rehabilitation, v.90, p.966-974, 2009.

McGOWAN, C. M.; STUBBS, N. C.; JULL, G. A. Equine physiotherapy: a comparative view of the science underlying the profession. Equine Veterinary Journal, v. 39, n. 1, p. 90-94, 2007a.

McGOWAN, C. M.; STUBBS, N. C.; HODGES, P.; JEFFCOTT, L. Back pain in horses: epaxial musculature. Canberra, Australian Capital Territory: Rural Industries Research and Development Corporation, 2007b.

McILWRAITH, C. W.; VAN WEEREN, R. Joint disease in the horse. Elsevier Health Sciences. cap. 1, p. 1-7, 2015.

MELO, U.P.; FERREIRA, C.; SANTIAGO, R.M.F.W. Balance the equine hoof. Ciência

Animal Brasileira, v.7, n.4, p. 389-398, 2006. (in Portuguese, with abstract in English).

MILLS, D. S.; NANKERVIS, K. J. Equine Behavior: Principles and Practice. 2. ed. Washington: Balckwell, 2000. 240p.

MIRÓ, F.; VIVO, J.; CANO, R.; DIZ, A.; GALISTEO, A.M. Walk and trot in the horse at driving: kinematic adaptation of its natural gaits. Animal Research, v.55, p.603-613, 2006.

MIYASHIRO, P. Comparação entre julgamento tradicional e avaliação cinemática do salto de cavalos da raça Brasileiro de Hipismo. 2012. 87f. Dissertação (Mestrado 
em Ciências) - Faculdade de Medicina Veterinária e Zootecnia da Universidade de São Paulo, São Paulo, 2012.

MOLENTO, C. F. M. Repensando as cinco liberdades. In: Congresso Internacional Conceitos Em Bem Estar Animal. 2006. Disponível em: <www.labea.ufpr.br/>. Acesso em: 17 de agosto de 2018.

MUYBRIDGE, E. Animals in motion. New York: Dover Publications, 2012.

NEBLETT, R; GATCHEL, J.R.; MAYER, G.T. A Clinical Guide to Surface-EMGAssisted Stretching as an Adjunct to Chronic Musculosketal Pain Rehabilitation, Applie Psychophysiology and Biofeedback, v.28, n.2, p. 147-160, 2001.

O'CONNOR, C.I.; NIELSEN, B.D.; SCHOTT, H.C. Effects of weight carrying, exercise

and a myo-anabolic supplement on growth and muscle. Equine Veterinary Journal, v.34, n.s34, p.178-181, 2002.

OLIVEIRA, K.; SOUTELLO, R. G. V.; DA FONSECA, R.; LOPES, A. M.; SANTOS, P. C. S.; FREITAS SANTOS, J. M.; VERA, J. H. V. Biometria por ultrassonografia da musculatura epaxial e pélvica em equinos treinados com rédea Pessoa. Ciência Rural, v. 44, n. 11, p. 2045-2051, 2014.

OLIVEIRA, K.; SOUTELLO, R. V.; DA FONSECA, R.; COSTA, C.; PAULO, R. D. L.; FACHIOLLI, D. F.; CLAYTON, H. M. Gymnastic training and dynamic mobilization exercises improve stride quality and increase epaxial muscle size in therapy horses. Journal of Equine Veterinary Science, v. 35, n. 11-12, p. 888-893, 2015.

OLIVEIRA, K. Restrição de Movimento: HorseMove método. 1. ed. Porto Alegre: Simplissimo, 2018. 75p.

OLIVEIRA, K. Pilates para cavalo: HorseMove método. 1. ed. Porto Alegre: Simplissimo, 2019. 42p.

OLIVEIRA, K.; PATINI, A.F.; ARAÚJO, M.S.; BOCCI, C.L. Ginástica laboral em cavalos terapeutas melhora a qualidade do movimento tridimensional do trote. Brazilian Journal of Biosystems Engineering 13, 2, 147-154. 2019.

PEHAM, C.; SCHOBESBERGER, H. Influence of the load of rider on a region of increased stiffness of the equine back: a modelling study. Equine Vet. J . 36, 703-705. 2004. 
PEHAM, C., LICKA, T., SCHOBESBERGER, H.; MESCHAM, E. Influence of the rider on the variability of the equine gait. Hum. Movement Sci. 23, 663-671. 2004.

PESSOA, G. O.; TRIGO, P.; NETO, F. D. M.; JUNIOR, A. C. L.; SOUSA, T. M.; MUNIZ, J. A.; MOURA, R. S. Comparative well-being of horses kept under total or partial confinement prior to employment for mounted patrols. Applied Animal Behaviour Science, v. 184, p. 51-58, 2016.

PIERCY, R. J. Muscle disorders of equine athletes. Equine Sports Medicine and Surgery E-Book, p. 189, 2013.

PILLINER, S.; ELMHURST, S.; DAVIES, Z. The horse in motion: The anatomy and physiology of equine Locomotion. John Wiley \& Sons, 2009, 207p.

RADAELLI, R.; WILHELM NETO, E. N.; MARQUES, M. F. B.; PINTO, R. S. Espessura e qualidade musculares medidas a partir de ultrassonografia: influência de diferentes locais de mensuração. Revista Brasileira de Cineantropometria e Desempenho Humano, v. 13, n. 2, p. 87-93, 2011.

REGATIERI, I. C.; MOTA, M. D. S. Horse breeding program: biochemical aspects. Ars veterinária, v. 28, n. 4, p. 227-233, 2012.

ROBERT, C. et al. The effects of treadmill inclination and speed on the activity of three muscle in the trotting horse. Equine Veterinary Journal, v.33, n.5, p.466-472, 2001.

ROBERT, C. et al. Effects of trotting speed on muscle activity and kinematics in saddlehorses. Equine Veterinary Journal, v.34, n.suppl, p.295-301, 2002.

ROEPSTORFF, L. et al. Kinetics and kinematics of the horse comparing left and right rising trot. Equine Veterinary Journal, v.41, n.3, p.292-296, 2009.

ROSA, L.R. Análise biomecânica de um cavalo de terapia: a interferência do peso corporal e da simetria postural do praticante na qualidade do passo do cavalo. In... XII Congresso Brasileiro de Equoterapia. Brasília, p.218-229, 2006.

SANROMÁN, L.J.F.; PETERSEN, H.R.; SANTIAGO, I.; de SEGURA, I.A.G.; BARREY, E. Gait analysis using 3D accelerometry in horses sedated with xylazine. The Veterinary Journal 193, 212- 216. 2012.

SCHILS, S.J. et al. Kinematic analysis of the equestrian - walk, posting trot and sitting trot. Human Movement Sciences, v.12, p.693-712, 1993. 
SJODIN, P.E; HERNLUND, E.; PFAU, T.; ANDERSEN, P.H.; RHODIN, M. Influence of seating styles on head and pelvic vertical movement symmetry in horses ridden at trot. Plos One. 2018.

SILVA, D.A; OLIVEIRA, K.; PEREIR, A.M.; DUARTE, A.C.A. Cinética do passo e do trote de cavalos treinados com e sem rédea Pessoa. Brazilian Journal of Biosystems Engineering 12, 3, 228-233. 2018.

SILVA, J. et al. Ginástica laboral: alongamento x flexionamento. Revista de Saúde e Biologia, v.1, n.2, p.6-12, 2006.

SILVA, M.N.G. et al. Levantamento das afecções ocorridas nos cavalos utilizados em equoterapia no período de 2006 a 2010 em Uruguaiana-RS. Revista Brasileira de Ciência Veterinária, v.19, n.3, p.139-143, 2012.

SISSON, S. Miologia geral. In: GETTY, R. Anatomia dos animais domésticos. v. 1, 5 ed. Rio de Janeiro: Guanabara Koogan, 1986b, p.38-46.

SISSON, S. Osteologia geral. In: GETTY, R. Anatomia dos animais domésticos. v. 1, 5 ed. Rio de Janeiro: Guanabara Koogan, 1986b, p.19-32.

SISSON, S. Osteologia equina. In: GETTY, R. Anatomia dos animais domésticos. v. 1, 5 ed. Rio de Janeiro: Guanabara Koogan, 1986b, p.233-323.

SOARES, C.M. Análise biomecânica do andamento de potros da raça Mangalarga Marchador aos 30 e 180 dias de idade. Dissertação. 2017.

STUBBS, N. C.; HODGES, P.W.; JEFFCOT, L.B. Functional anatomy of the caudal thoracolumbar and lumbosacral spine in the horse. Equine Veterinary Journal, v. 38, n.s36, p. 393-399, 2006.

STUBBS, N. C.; CLAYTON, H. M. Activate your horse's core: Unmounted Exercises for Dynamic Mobility, Strength, \& Balance. Michigan: Sport Horse Publications, p. 5-9, 2008.

STUBBS, N. C.; RIGGS, C.M.; HODGES, P.W. Osseous spinal pathology and epaxial muscle ultrasonography in Thoroughbred racehorses. Equine Veterinary Journal, v. 42 ,

(Suppl. 38), p. 654-661, 2010.

STUBBS, N. C.; KAISER, L. J.; HAUPTMAN, J.; CLAYTON, H. M. Dynamic mobilization exercise increase cross sectional area of Musculus Multifidus. Equine Veterinary Journal, v. 43, n. 5, p. 522-529, 2011.

SVOBODA, Z. et al. Does the rider influence the horses movement in hippotherapy? Acta University Palacki. Olomuc. Gymn., v.41, n.4, p.37-41, 2011. 
TABOR, G. The effect of dynamic mobilization exercises on the equine multifidus muscle and thoracic profile. Tese de doutorado, Universidade de Plymouth, Plymouth/UK, 2015.

WAKELING, J.M. Segmental variation in the activity and function of the equine longissimus dorsi muscle during walk and trot. Equine and Comparative Exercise Physiology, v.4, n.2, p.95-103, 2007.

WALDERN, N.M.; WIESTNER, T.; PEINEN, K. Influence of different head-neck positions on vertical ground reaction forces, linear and time parameters in the unridden horse walking and trotting on a treadmill. Equine Veterinary Journal, v.41, n.3, p.268-

$273,2009$.

ZADNIKAR, M.; KASTRIN,A. Effects of hippotherapy and therapeutic horseback riding on postural control or balance in children with cerebral palsy: a meta-analysis. Developmental Medicine \& Child Neurology, 53: 684-691, 2011.

ZSOLDOS, R.R.; KOTSCHWAR, A.; KOTSCHWAR, A.B. Activity of equine rectus abdominis and oblique external abdominal muscles measured by surface EMG during walk and trot on the treadmill. Equine Veterinary Journal, v.42, n. suppl. 38, p.523$529,2010$. 


\section{SOBRE A AUTORA}

Kátia de Oliveira graduou-se Zootecnista na Faculdade de Medicina Veterinária e Zootecnia da Universidade Estadual Paulista - UNESP/Campus de Botucatu em 1993. Tornou-se Doutora pela mesma instituição em 2004, no qual iniciou a sua linha de pesquisa na área da Ciência Equina Esportiva, com a publicação de vários artigos científicos na área.

Em 1994 iniciou sua atividade como docente, primeiramente, na Universidade de Marília - UNIMAR e, e posteriormente, na Faculdade de Ciências Agrárias e Tecnológicas da UNESP/Campus de Dracena, onde exerce ainda sua função como Professora Assistente Doutora da disciplina de Equideocultura.

A Professora Kátia possui quinze anos de experiência na preparação física muscular e biomecânica de cavalos atletas, dos quais pode citar: Treinamento em avaliação biomecânica, certificado pelo Centaure Metrix, França; Treinamento em terapia física manual (massagem, alongamento e Pilates em cavalos), certificado pela Horse Inside Out, Inglaterra.

Certificada pela Horses Inside Out no CPD para Terapeutas, na Faculdade de Derby, Inglaterra, habilitando-se em Avaliação Musculoesquelética e Mobilização Articular, Palpação e Técnicas Avançadas em Tecidos Moles, Avaliação do Movimento e da Postura.

Recentemente, esteve realizando capacitação na área de Dissecação Anatômica da Coluna, Cabeça e Segmentos Apendiculares de Equinos, na Hartpury College, Gloucester, Inglaterra. 


\section{GINÂSTICA LABORAL PARA}

CAVALOS TERAPEUTAS

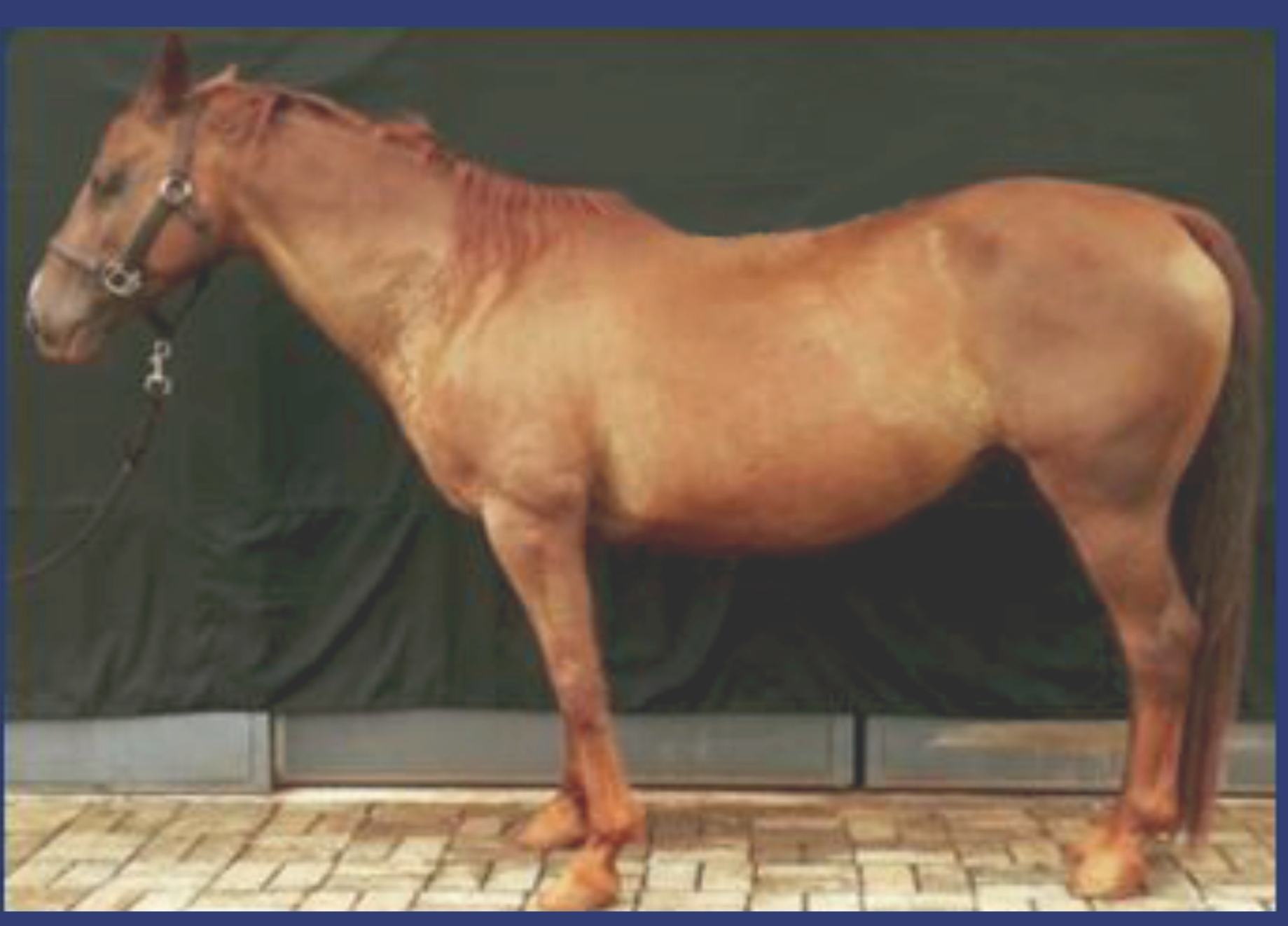

REVISÃO CIENTIIFICA

Prof ${ }^{a}$. Ora. Kátia de Oliveira 